Published in ASCE Journal of Geotechnical and Geoenvironmental Engineering, 139(9):1554-1566. http://dx.doi.org/10.1061/(ASCE)GT.1943-5606.0000882

\title{
$1 \quad$ Critical skirt spacing for shallow foundations under general loading
}

3 Divya S.K. MANA

4 Centre for Offshore Foundation Systems (M053) and ARC Centre of Excellence for

5 Geotechnical Science and Engineering

6 University of Western Australia

$7 \quad$ Email: 20674905@student.uwa.edu.au

8

9 Susan GOURVENEC (corresponding author)

10 Centre for Offshore Foundation Systems (M053) and ARC Centre of Excellence for

11 Geotechnical Science and Engineering

12 University of Western Australia

1335 Stirling Highway, Crawley

14 Perth, WA 6009

15 Australia

16 Tel: +61 864883995

17 Fax: +61 864881044

18 Email: susan.gourvenec@uwa.edu,au

19 Christopher M. MARTIN

20 Department of Engineering Science

21 University of Oxford

22 Email: chris.martin@eng.ox.ac.uk

23

24 No. of words: 5607 (without abstract, acknowledgements and references)

25 No. of tables: 0

26 No. of figures: 23

27 
Published in ASCE Journal of Geotechnical and Geoenvironmental Engineering, 139(9):1554-1566. http://dx.doi.org/10.1061/(ASCE)GT.1943-5606.0000882

\section{Abstract}

29 Finite element limit analysis is used to identify the critical internal skirt spacing for

30 undrained failure of shallow skirted foundations under conditions of plane strain, based

31 on the criterion that the confined soil plug should ideally displace as a rigid block, such

32 that optimal bearing capacity is realized. General loading (vertical, horizontal and

33 moment) is considered for foundations with skirt embedments ranging from 5\% to 50\%

34 of the foundation breadth, in soil having either uniform strength or strength proportional

35 to depth. The results explicitly identify the number of internal skirts required to ensure

36 soil plug rigidity under arbitrary combinations of horizontal and moment loading,

37 expressed as a function of the normalized skirt embedment and the maximum expected

38 level of vertical loading (as a fraction of the ultimate vertical bearing capacity). It is

39 shown that fewer internal skirts are required with increasing normalized foundation

40 embedment, but more internal skirts are required if the soil strength increases with

41 depth. The results also indicate the potential for a significant reduction in capacity if

42 insufficient skirts are provided, such that plastic deformation is permitted to occur

43 within the soil plug.

44

45 Key words: Offshore structures; Limit analysis; Shallow foundations; Failure loads 
Published in ASCE Journal of Geotechnical and Geoenvironmental Engineering, 139(9):1554-1566. http://dx.doi.org/10.1061/(ASCE)GT.1943-5606.0000882

\section{Introduction}

Skirted shallow foundations are comprised of a main foundation base plate with relatively slender vertical plates (typically both peripheral and internal) protruding below. These 'skirts' penetrate into the seabed, with the aim of confining a block of surficial soil referred to as the soil plug. A cross-section through an idealized skirted foundation is shown in Figure 1. In order to achieve maximum capacity, sufficient internal skirts should be provided to ensure that the soil plug displaces as a rigid body

54 during plastic failure of the foundation. If too few internal skirts are provided, failure mechanisms involving deformation within the soil plug may occur, leading to a reduction in load-carrying capacity. Figure 2 illustrates some examples of these potential 'internal mechanisms', as compared with the behavior of a corresponding solid foundation, for the simplified cases of pure vertical and pure horizontal loading. In the examples shown, deformation within the soil plug occurs when there are no internal skirts and when a single internal skirt is provided, while the provision of two (or more)

61 internal skirts results in the same failure mechanism as that induced by the solid 62 foundation.

Previous research has shown that for foundations with peripheral skirts only, an internal mechanism is unlikely to occur for deep skirts and a uniform profile of undrained strength with depth, but the potential is increased for shallow skirts and a high degree of strength heterogeneity (Yun and Bransby 2007, Bransby and Yun 2009, Mana et al.

67 2010). Although these previous works have identified the foundation configurations and soil conditions most susceptible to the development of internal mechanisms, the question of the number of internal skirts required to ensure rigid soil plug behavior - 
Published in ASCE Journal of Geotechnical and Geoenvironmental Engineering, 139(9):1554-1566. http://dx.doi.org/10.1061/(ASCE)GT.1943-5606.0000882

70 whether for idealized cases of uniaxial loading or more realistic combinations of general

71 loading - has not been addressed to date.

72 Despite the potential for plastic deformation to occur within the soil plug, skirted

73 foundations are often treated as embedded solid foundations when assessing ultimate

74 capacity, on the basis that sufficient internal skirts have been provided to ensure that the

75 soil plug displaces rigidly. For example, the assumption of a solid, rigid foundation is

76 inherent in the classical bearing capacity calculation methods presented in current

77 recommended practices and industry guidelines (e.g. API 2000, ISO 2003). If, however,

78 the provision of internal skirts is insufficient, the critical collapse mechanism will

79 extend into the soil plug, resulting in a load-carrying capacity that is smaller than the

80 anticipated design value.

81 This paper presents results from a comprehensive numerical investigation of the critical

82 number of internal foundation skirts required to ensure that the soil plug confined within

83 a skirted foundation displaces as a rigid block, thus ensuring that the maximum load-

84 carrying capacity of the foundation can be realized.

\section{Scope of study}

$86 \quad 2.1 \quad$ Foundation geometry

87 This study considers both solid and skirted shallow foundations with embedment to

88 breadth ratios, $d / B$, between $5 \%$ and $50 \%$. The range of embedment ratio was selected

89 to represent a range encountered in the field, for example shallow foundations for

90 subsea systems typically lie in the range $0.05 \leq \mathrm{d} / \mathrm{B} \leq 0.2$ while foundations for fixed-

91 bottom or buoyant platforms typically lie in the range $0.2 \leq \mathrm{d} / \mathrm{B} \leq 0.5$. For the skirted 
Published in ASCE Journal of Geotechnical and Geoenvironmental Engineering, 139(9):1554-1566. http://dx.doi.org/10.1061/(ASCE)GT.1943-5606.0000882

92 foundations, the peripheral and internal skirts are modeled with a thickness to breadth

93 ratio $\mathrm{t} / \mathrm{B}=0.001$ and are positioned with uniform spacing, $\mathrm{s}$, across the foundation base

94 plate. The modeled skirt thickness ratio represents a value towards the lower end of the

95 range used in the field (e.g. Bye et al. 1995, Erbrich and Hefer 2002) and has been

96 selected to minimize the effect of the geometry of the skirts on the calculated bearing

97 capacities and failure mechanisms. A foundation with peripheral skirts only is referred

98 to as having 'zero internal skirts'. Figure 3 shows the modeled geometry and the

99 nomenclature adopted in this paper.

100 In practice, skirted foundations and/or the distribution of internal skirts may often adopt

101 a three-dimensional arrangement. Skirted foundations for gravity base structures,

102 jackets or buoyant facilities are likely to be quasi-circular or rectangular with length to

103 breadth aspect ratio L/B between 1 and 2 while subsea foundations are likely to be

104 rectangular, also with L/B between 1 and 2.

105 However, plane strain modeling is considered adequate for the purpose of this study,

106 where the focus is identifying underlying mechanisms. Failure mechanisms dominated

107 by sliding and rotation are essentially in-plane and therefore shape effects of three-

108 dimensional foundation geometry would not be expected to be significant. Failure

109 mechanisms with a significant axisymmetric component, such as vertical bearing

110 failure, would be expected to be more significantly affected by three dimensional

111 effects, although design situations with vertical load close to critical values are perhaps

112 unlikely. When considering foundations with a length to breadth aspect ratio greater

113 than 1, it should be borne in mind that the effective embedment ratio for loading acting

114 perpendicular to the long edge is defined by $d / L$ rather than $d / B$, such that closer 
Published in ASCE Journal of Geotechnical and Geoenvironmental Engineering, 139(9):1554-1566. http://dx.doi.org/10.1061/(ASCE)GT.1943-5606.0000882

115 spacing of skirts may be required along the long axis of the foundation compared with

116 the short axis. It is probable that three-dimensional effects, if relevant, would increase

117 the stability of the soil plug, such that a prediction of critical skirt spacing - or the

118 minimum required number of internal skirts - based on plane strain conditions would

119 lead to a design erring on the safe side.

120

\subsection{Soil properties}

121 The soil is modeled as a rigid-plastic, purely cohesive material, such that its response is

122 defined completely in terms of the undrained shear strength, $\mathrm{s}_{\mathrm{u}}$. In the field, the

123 variation of strength with depth can often be approximated with sufficient accuracy as a

124 linear function. The degree of strength heterogeneity can then be defined in terms of the

125 dimensionless group $\mathrm{kB} / \mathrm{sum}$, where $\mathrm{k}$ is the gradient of the strength profile, $\mathrm{B}$ is the

126 foundation breadth and sum is the mudline strength intercept. In this study two limiting

127 strength profiles are considered: uniform $\left(\mathrm{kB} / \mathrm{s}_{\mathrm{um}}=0\right)$ and linearly increasing with depth

128 from zero strength at the mudline $\left(\mathrm{kB} / \mathrm{sum}_{\mathrm{um}}=\infty\right)$. These two cases are illustrated

129 schematically in Figure 4.

130

\subsection{Interface conditions}

131 The skirted foundations are modeled as perfectly smooth, such that no shear stress can

132 be mobilized along the foundation-soil interface (roughness factor $\alpha=0$ ). This is to

133 ensure that the capacity calculations are conservative with respect to interface strength

134 (in practice it is more usual to assume $\alpha=0.3$ to 0.8 ). The extent of the smooth interface

135 includes all surfaces in contact with the soil: the external and internal skirt faces, the

136 skirt tips and the underside of the foundation base plate. 
Published in ASCE Journal of Geotechnical and Geoenvironmental Engineering, 139(9):1554-1566. http://dx.doi.org/10.1061/(ASCE)GT.1943-5606.0000882

137 The solid foundations are modeled with smooth sides $(\alpha=0)$ and fully rough bases $(\alpha=$

138 1). The rough base of the solid foundation is intended to be comparable with the soil-on-

139 soil shearing surface that develops at the base of a skirted foundation, assuming

140 sufficient internal skirts have been provided.

141 In all cases the foundation-soil interface is taken to be fully bonded, i.e. unlimited

142 tensile normal stresses can be mobilized between the foundation and the soil. It is well

143 established that negative excess pore pressures can develop between the underside of

144 the foundation base plate and the soil plug, allowing transient uplift to be resisted

145 (Dyvik et al. 1993, Andersen and Jostad 1999, Watson et al. 2000, Gourvenec et al.

146 2009, Mana et al. 2012). A ‘zero-tension’ interface is not considered here since, should

147 a gap form, local drainage would take place in the vicinity of the foundation, and the

148 duration over which the negative excess pore pressures in the soil plug could be relied

149 upon to resist transient uplift loads would be compromised. The assumption of

150 undrained behavior, as adopted in this study, would therefore be invalid. It is

151 acknowledged that gapping between the foundation skirts and the adjacent soil may

152 occur, particularly when a foundation is subjected to predominantly horizontal loading

153 in soil with a low degree of strength heterogeneity. However, the potential for gapping

154 is a separate consideration in the design process.

\section{$155 \quad 2.4 \quad$ Loading}

156 The solid and skirted foundations are modeled as discrete rigid bodies with a single load

157 reference point located on the centerline of the foundation at mudline level. The sign

158 convention for combined vertical, horizontal and moment loading $(\mathrm{V}, \mathrm{H}, \mathrm{M})$ is defined

159 in Figure 5. 
Published in ASCE Journal of Geotechnical and Geoenvironmental Engineering, 139(9):1554-1566. http://dx.doi.org/10.1061/(ASCE)GT.1943-5606.0000882

160 Figure 6 shows the procedure used to establish failure envelopes for combined loading.

161 Initial analyses involving pure vertical loading are used to identify the vertical bearing

162 capacity, $\mathrm{V}_{\text {ult, }}$ of each foundation. Ultimate limit states for combined loading are then

163 identified by conducting radial probes in M/B:H space at constant $\mathrm{V}$. These probes are

164 defined by an angle $\theta$ (see Figure 6) and are applied at $5^{\circ}$ intervals from $0^{\circ}$ to $180^{\circ}$.

165 Various levels of vertical load are considered, relative to the uniaxial vertical capacity

166 of the corresponding solid foundation: $\mathrm{V} / \mathrm{V}_{\mathrm{ult}}=0,0.1,0.25,0.5$ and 0.75 . For each

167 probe, lower and upper bound collapse loads are computed as described in the following

168 section. The respective solution points are joined as shown in Figure 6 to give lower and

169 upper bound failure envelopes for each plane of constant $\mathrm{V} / \mathrm{V}_{\text {ult }}$.

170 The soil and the foundations are all modeled as weightless materials, thus ensuring that

171 geostatic equilibrium is automatically satisfied at the start of each analysis. When

172 applying these results in practice, the total weight of the foundation (minus the total

173 weight of displaced soil) should be included as part of the applied vertical force, $\mathrm{V}$.

\section{Finite element limit analysis}

175 All analyses were performed using OxLim, a finite element limit analysis (FELA) program developed at Oxford University. FELA differs from conventional finite

177 element analysis in that it implements the classical bound theorems of limit analysis,

178 rather than computing an approximate plastic collapse load that is approached

179 incrementally. With FELA it is usual to compute both lower bound and upper bound

180 plasticity solutions for a given problem, thus bracketing the range in which the exact collapse load must lie. Background information about the FELA method and its 
Published in ASCE Journal of Geotechnical and Geoenvironmental Engineering, 139(9):1554-1566. http://dx.doi.org/10.1061/(ASCE)GT.1943-5606.0000882

182 historical development can be found in the papers by Makrodimopoulos \& Martin

183 (2006, 2007) which deal with lower bound FELA and upper bound FELA respectively.

184 Both of these papers contain extensive reviews of the relevant literature, with an

185 emphasis on applications of FELA to geotechnical problems.

186 OxLim implements various calculation methods that are described in detail by

187 Makrodimopoulos and Martin (2006, 2007, 2008). The program also uses a simple

188 strategy for adaptive mesh refinement (Martin 2011) that facilitates rapid convergence

189 of the lower and upper bound solutions. At each stage of the refinement process, which

190 is fully automatic, lower and upper bounds are computed using the same mesh. The

191 current version of OxLim relies on two key pieces of software by others: MOSEK

192 (MOSEK ApS 2010) for optimization and Triangle (Shewchuk 2002) for unstructured

193 triangular mesh generation.

194 Essentially, each lower bound solution involves optimization of a stress field that

195 satisfies equilibrium but does not exceed the shear strength of either the soil or the

196 foundation-soil interface. Each upper bound solution involves optimization of a

197 velocity field that is compatible with the motion of the footing (which has three degrees

198 of freedom in plane strain) and generates a strain field that satisfies the associated flow

199 rule. The finite elements employed in OxLim are as follows: three-noded triangles

200 (linear interpolation of stress) for the lower bound analyses, and six-noded triangles

201 (quadratic interpolation of velocity) for the upper bound analyses. Further details are

202 given in the papers by Makrodimopoulos and Martin (2006, 2007). For the purely

203 cohesive soil considered in this paper, enforcement of the associated flow rule in the 
Published in ASCE Journal of Geotechnical and Geoenvironmental Engineering, 139(9):1554-1566. http://dx.doi.org/10.1061/(ASCE)GT.1943-5606.0000882

204 upper bound analyses is achieved by constraining the volumetric strain to be zero

205 throughout the soil, and the normal displacement jump to be zero on all interfaces.

206 In the present OxLim analyses the solid and skirted foundations were 'wished in place',

207 with no attempt to account for the surface heave that would occur during continuous

208 penetration from the surface. The extent of the modeled soil domain (width $\times$ depth)

209 was $4 \mathrm{~B} \times 2 \mathrm{~B}$ for all the analyses except for pure vertical loading $(6 \mathrm{~B} \times 2 \mathrm{~B})$, which was

210 comfortably sufficient to contain the plastically deforming region for all embedment

211 ratios and load combinations. The initial mesh sizing was an iterative process where the

212 domain was defined, the analysis run and the domain was extended and the analysis re-

213 run if the mechanism was impacted by the boundaries of the domain. The target element

214 size (triangle side length) for generation of the initial mesh was $0.5 \mathrm{~B}$ for the vertical

215 loading cases and 0.3B for all other analyses, which is 0.1 times the average bounding

216 box dimension. In each OxLim analysis, several cycles of automated adaptive mesh

217 refinement (typically two or three) were performed until the lower and upper bound

218 solutions bracketed the exact collapse load to within $\pm 1 \%$, i.e., until the percentage

219 bracketing error, defined as $(\mathrm{UB}-\mathrm{LB}) /(\mathrm{UB}+\mathrm{LB}) \times 100$, was smaller than $1 \%$.

220 Although this level of bracketing can readily be achieved for undrained bearing capacity

221 problems, it is not worthwhile seeking even better precision because in practice the

222 uncertainty associated with selection of the design shear strength profile is inevitably

223 much greater. 
Published in ASCE Journal of Geotechnical and Geoenvironmental Engineering, 139(9):1554-1566. http://dx.doi.org/10.1061/(ASCE)GT.1943-5606.0000882

\section{Results}

225 All results are presented in terms of normalized quantities. The geometric characteristics 226 of the foundations are defined by the embedment ratio, $d / B$, and the skirt spacing ratio,

227 s/B (see Figure 3). The bearing capacity failure envelopes, or interaction diagrams, are presented in terms of the dimensionless loads $\mathrm{V} / \mathrm{Bs}_{\mathrm{u}}, \mathrm{H} / \mathrm{Bs}_{\mathrm{u}}$ and $\mathrm{M} / \mathrm{B}^{2} \mathrm{~s}_{\mathrm{u}}$ (for uniform strength) or $\mathrm{V} / \mathrm{B}^{2} \mathrm{k}, \mathrm{H} / \mathrm{B}^{2} \mathrm{k}$ and $\mathrm{M} / \mathrm{B}^{3} \mathrm{k}$ (for strength proportional to depth). The one exception is that the vertical bearing capacities in Figure $8 \mathrm{~b}$ are normalized by the local strength at skirt tip level, $\mathrm{su}_{\mathrm{u}}=\mathrm{kd}$, in order to illustrate more clearly the effect of the number of internal skirts on the familiar bearing capacity factor $\mathrm{N}_{\mathrm{c}}$.

\subsection{Validation}

234 The first validation exercise was to confirm that OxLim produced correct results for the vertical bearing capacity of a surface strip footing on soil with uniform strength $\left(\mathrm{kB} / \mathrm{s}_{\mathrm{um}}\right.$

$236=0)$ and strength proportional to depth $\left(\mathrm{kB} / \mathrm{s}_{\mathrm{um}}=\infty\right)$. In both cases exact analytical

237 solutions are available, $\mathrm{V}_{\mathrm{ult}} / \mathrm{Bs}_{\mathrm{u}}=2+\pi$ (Prandtl 1921) and $\mathrm{V}_{\mathrm{ult}} / \mathrm{B}^{2} \mathrm{k}=1 / 4$ (Davis and

238 Booker 1973), and both results are independent of the footing roughness. As expected,

239 the lower and upper bound solutions obtained from OxLim were found to bracket each

240 of these exact solutions to within the target bracketing precision of $\pm 1 \%$.

241 In terms of validation against established (albeit numerical) results, Figure 7 compares

242 some combined loading failure envelopes obtained using Oxlim with those obtained

243 using the commercial finite element software Abaqus (Dassault Systèmes 2009) given

244 by Gourvenec and Barnett (2011). The problem considered is the basic case of a rough

245 strip footing on the surface of a soil deposit with uniform strength. Figure 7 shows that 
Published in ASCE Journal of Geotechnical and Geoenvironmental Engineering, 139(9):1554-1566. http://dx.doi.org/10.1061/(ASCE)GT.1943-5606.0000882

246 there is good overall agreement between the two methods. Furthermore, for each value

247 of $\mathrm{V} / \mathrm{V}_{\mathrm{ult}}$, the lower and upper bound failure envelopes from OxLim lie very close

248 together, demonstrating that even for general loading conditions, tight numerical

249 bracketing of the exact solution was achieved using FELA.

250

251

252

253

254

255

256

257

258

259

260

261

262

263

264

265

266

\section{$4.2 \quad$ Vertical loading}

Figure 8 compares vertical bearing capacity factors for solid and skirted foundations as a function of embedment ratio, for both uniform strength $\left(\mathrm{kB} / \mathrm{s}_{\mathrm{um}}=0\right)$ and strength proportional to depth $\left(\mathrm{kB} / \mathrm{s}_{\mathrm{um}}=\infty\right)$. In the latter case, the vertical capacity $\mathrm{V}_{\text {ult }}$ is normalized with respect to $\mathrm{su}_{\mathrm{u}}$, the strength at depth d, as this best illustrates the variation of bearing capacity as a function of the number of internal skirts at low $d / B$, and the convergence of bearing capacity with increasing $\mathrm{d} / \mathrm{B}$. Also with respect to Figure 8b, it should be noted that in the reduction in bearing capacity factor with increasing embedment ratio is an effect of normalization by an ever-increasing strength at skirt tip level; the actual bearing capacity $V_{\text {ult }}$ increases with d/B. In Figure 8 average values of the lower and upper bound solutions from OxLim are shown.

Figure 8a shows that in uniform soil, the vertical bearing capacity of a foundation with peripheral skirts only (i.e. zero internal skirts) is equal to that of a solid embedded foundation, indicating that the soil plug displaces rigidly even without the provision of internal skirts. By contrast, Figure 8b shows that in soil with strength proportional to depth, the bearing capacity is markedly affected by the absence or provision of internal skirts, particularly for embedment ratios $\mathrm{d} / \mathrm{B}<0.3$. 
Published in ASCE Journal of Geotechnical and Geoenvironmental Engineering, 139(9):1554-1566. http://dx.doi.org/10.1061/(ASCE)GT.1943-5606.0000882

267 The trends of the bearing capacity factors presented in Figure 8 are reflected in the

268 mechanisms accompanying failure. For soil with uniform strength, the solid and

269 externally skirted foundations exhibit identical mechanisms over the full range of

270 embedment ratios considered $(0.05 \leq \mathrm{d} / \mathrm{B} \leq 0.5)$. Figure 9 illustrates these mechanisms

271 for selected embedment ratios of $d / B=0.1$ and 0.5 . The similarity of the mechanisms

272 for the solid and skirted foundations echoes the similarity of the bearing capacity

273 factors. For soil with strength proportional to depth, the difference in bearing capacity

274 factor (as seen in Figure 8b, d/B < 0.3) arises from a difference in failure mechanism.

275 Significant plastic deformation can now take place within the soil plug, particularly at

276 low embedment ratios, as illustrated for an example case, $d / B=0.1$, in Figure 10. It is

277 however possible for the soil plug of a skirted foundation in soil with a high degree of

278 strength heterogeneity to behave rigidly in the absence of internal skirts, provided the

279 embedment is sufficient. This is clear from the mechanisms in Figure $11\left(\mathrm{kB} / \mathrm{s}_{\mathrm{um}}=\infty\right.$

280 and $d / B=0.5$ ) and is reflected in the convergence of the various curves in Figure $8 \mathrm{~b}$ for

281 embedment ratios $\mathrm{d} / \mathrm{B}>0.3$.

282 The results presented in Figure 8 to 11 are consistent with existing theoretical solutions.

283 Broadly speaking, for a skirted foundation, an internal failure mechanism would not be

284 expected to develop when a Prandtl-type mechanism governs failure of the

285 corresponding solid foundation, but it would be expected when a Hill-type mechanism

286 governs failure. (Prandtl- and Hill-type mechanisms are illustrated schematically in

287 Figure 12) For surface foundations $(\mathrm{d} / \mathrm{B}=0)$ it is well established that a Hill-type

288 mechanism governs failure of smooth footings and becomes critical for rough footings

289 when the degree of strength heterogeneity, quantified by the dimensionless group

$290 \mathrm{kB} / \mathrm{sum}$, reaches a threshold of approximately 1 (Kusakabe et al. 1986). A similar trend 
Published in ASCE Journal of Geotechnical and Geoenvironmental Engineering, 139(9):1554-1566. http://dx.doi.org/10.1061/(ASCE)GT.1943-5606.0000882

291 has been noted for embedded solid foundations, with a Hill-type mechanism being

292 critical for smooth-based embedded foundations and having the potential to become

293 critical for rough-based embedded foundations, particularly in the presence of a

294 strength heterogeneity ratio larger than 1 or 2 (Martin and Randolph 2001). Because

295 skirted foundations are essentially rough-based due to the soil-on-soil interface at skirt

296 tip level, a Prandtl-type mechanism would be expected to govern vertical bearing

297 capacity failure in a soil having uniform strength with depth, while a Hill-type

298 mechanism would be expected in a deposit having a highly heterogeneous strength

299 profile - as was observed in the FELA analyses undertaken for this study.

\subsection{General loading}

301 Failure envelopes in normalized H-M load space were calculated in selected planes of

302 constant $\mathrm{V}$, expressed as a percentage of the uniaxial vertical capacity, $\mathrm{V}_{\text {ult, }}$ of a

303 corresponding solid foundation. Failure envelopes for a solid foundation, and for skirted

304 foundations with up to eight internal skirts, were calculated for all combinations of the

305 following parameters:

306

- $\quad$ embedment ratio $\mathrm{d} / \mathrm{B}=0.05,0.1,0.2,0.3$ and 0.5

307

- $\quad$ shear strength gradient $\mathrm{kB} / \mathrm{sum}_{\mathrm{um}}=0$ and $\infty$

308

- $\quad$ vertical load level $\mathrm{V} / \mathrm{V}_{\text {ult }}=0,0.1,0.25,0.5$ and 0.75

309 In each case, OxLim was used to perform a series of radial probes as shown in Figure 6,

310 resulting in both lower bound and upper bound failure envelopes. For clarity, however,

311 only the upper bound envelopes are plotted in the figures below.

312 Examples of the calculated failure envelopes are illustrated in Figure 13 to 16 for two

313 selected embedment ratios $(\mathrm{d} / \mathrm{B}=0.1$ and 0.5$)$, both strength profiles $\left(\mathrm{kB} / \mathrm{sum}_{\mathrm{um}}=0\right.$ and $\left.\infty\right)$ 
Published in ASCE Journal of Geotechnical and Geoenvironmental Engineering, 139(9):1554-1566. http://dx.doi.org/10.1061/(ASCE)GT.1943-5606.0000882

314 and three selected vertical load levels $\left(\mathrm{V} / \mathrm{V}_{\text {ult }}=0,0.5\right.$ and 0.75$)$. The interpreted results

315 for the whole study are summarized in Figure 22and 23, and are discussed in detail in

316 the section 'Design Recommendations'.

317 In Figure 13 to 16 generally, the innermost failure envelope corresponds to a foundation

318 with peripheral skirts only. The addition of internal skirts leads to an increase in load-

319 carrying capacity, which is reflected in expansion of the $\mathrm{H}-\mathrm{M}$ failure envelope on each

320 plane of constant $\mathrm{V}$. The outermost failure envelope corresponds to the rough-based

321 solid foundation that defines the optimum, maximum load-carrying capacity (and is in

322 most cases coincident with the failure envelope for a skirted foundation with sufficient

323 internal skirts).

324 Figure 13 shows failure envelopes for a foundation with shallow skirts $(d / B=0.1)$ in

325 uniform soil $\left(\mathrm{kB} / \mathrm{sum}_{\mathrm{um}}=0\right)$. In the absence of vertical load $\left(\mathrm{V} / \mathrm{V}_{\mathrm{ult}}=0\right)$ a single internal

326 skirt is sufficient to ensure that the soil plug displaces rigidly under any combination of

327 horizontal and moment load, such that optimal capacity is achieved. With increasing

328 vertical load, additional internal skirts are required to ensure plug rigidity under all

329 combinations of $\mathrm{H}$ and $\mathrm{M}$. When $\mathrm{V} / \mathrm{V}_{\text {ult }}=0.75$, loading ratios $\mathrm{M} / \mathrm{B}: \mathrm{H} \approx 0.3$ to 2.0 are

330 critical - i.e. they require the largest number of internal skirts before reaching the

331 maximum capacity. Strictly speaking, the optimal configuration requires five internal

332 skirts, though little improvement in capacity is achieved with more than two skirts.

333 Figure 14 shows corresponding failure envelopes for a foundation with deeper skirts

$334(d / B=0.5)$ in soil with uniform strength. In this case low vertical loads are critical,

335 requiring one internal skirt to ensure soil plug rigidity, while under higher vertical loads 
Published in ASCE Journal of Geotechnical and Geoenvironmental Engineering, 139(9):1554-1566. http://dx.doi.org/10.1061/(ASCE)GT.1943-5606.0000882

336 the optimal solid foundation capacity is achieved for all directions of loading in $\mathrm{H}-\mathrm{M}$

337 space, even if no internal skirts are provided.

338 Figure 15 and 16 show that when the soil strength is proportional to depth $\left(\mathrm{kB} / \mathrm{sum}_{\mathrm{um}}=\infty\right)$,

339 more internal skirts are required, particularly when the skirt embedment ratio is low, as

340 in Figure 15. This would be expected since with this type of strength profile, there is a

341 strong tendency for the failure mechanism to propagate into the softer, near-surface soil.

342 In fact, Figure 15 shows that six or more internal skirts are required to ensure soil plug

343 rigidity for a foundation with $\mathrm{d} / \mathrm{B}=0.1$ in soil with strength proportional to depth -

344 twice as many as are required with the same embedment ratio in a deposit with uniform

345 strength (cf. Figure 13). When the skirts are longer, Figure 16 (for $\mathrm{d} / \mathrm{B}=0.5$ ) shows that

346 failure to provide any internal skirts leads to a significant loss of capacity with respect

347 to the optimum. However, there is little benefit in providing more than one internal

348 skirt, since this is sufficient to achieve maximum capacity for nearly all loading

349 directions in H-M space, at all levels of vertical load.

350 It is noteworthy that optimal foundation capacity of a skirted foundation may fall short

351 of the capacity of a rough-based solid foundation with the same embedment ratio,

352 particularly for shallow embedment in soil with a high degree of strength heterogeneity.

353 That is, addition of further skirts does not lead to an incremental increase in capacity

354 and the maximum capacity obtained is less than that for an equivalent rough-based solid

355 foundation. In the case of zero mudline strength $\left(\mathrm{kB} / \mathrm{sum}_{\mathrm{um}}=\infty\right)$ the failure mechanism at

356 skirt tip level may be affected by the potential zero-strength failure plane on the

357 underside of the foundation base plate; a smooth foundation-soil interface would have

358 the same effect in soil with a non-zero mudline strength. In this study, a smooth skirted 
Published in ASCE Journal of Geotechnical and Geoenvironmental Engineering, 139(9):1554-1566. http://dx.doi.org/10.1061/(ASCE)GT.1943-5606.0000882

359 foundation gave inferior V-H-M capacity, compared with a smooth-sided rough-based

360 solid foundation of equal embedment ratio, when $\mathrm{d} / \mathrm{B}=0.05$, i.e. convergence of the

361 failure envelopes of the skirted foundations with $n$ and $n+1$ internal skirts occurred at a

362 lower ultimate limit state than that achieved by the solid foundation (Figure 17).

363 However, when the embedment ratio exceeds a critical value $(0.05<\mathrm{d} / \mathrm{B} \leq 0.1$ in this

364 study) the effect of soil-on-soil shearing at skirt tip level becomes sufficiently remote

365 from the zero-strength underside of the foundation base plate, and equal bearing

366 capacity can be mobilized by a smooth skirted foundation and a smooth-sided rough-

367 based solid foundation. In the limit of an infinite number of smooth-sided, smooth-

368 tipped internal skirts being provided, the capacity of a skirted foundation would tend

369 towards that of a smooth-based solid foundation. In practice, with normalized skirt

370 thicknesses rarely exceeding $\mathrm{t} / \mathrm{B}=0.01$, the ratio of total skirt tip area to overall

371 foundation area would typically be less than $5 \%$.

372 Failure envelopes for combined loading, such as those in Figure 13 to 16, show that the

373 number of internal skirts is always critical for 'positive' combinations of H-M loading,

374 i.e. $\mathrm{H}$ and $\mathrm{M}$ both acting in their positive directions (according to the sign convention

375 defined in Figure 5). This is of course the case in nearly all practical situations, with

376 moment loading arising from horizontal loads acting on the superstructure at various

377 lever arms above the mudline. Furthermore, the number of internal skirts is critical

378 mostly at high levels of vertical load $\left(\mathrm{V} / \mathrm{V}_{\text {ult }}=0.5\right.$ or greater $)$, indicating potential

379 efficiencies if the applied vertical loads are known to be limited - as is often the case for

380 skirted mat foundations for subsea structures. 
Published in ASCE Journal of Geotechnical and Geoenvironmental Engineering, 139(9):1554-1566. http://dx.doi.org/10.1061/(ASCE)GT.1943-5606.0000882

381 The failure mechanisms occurring under general loading confirm the trends observed in

382 the failure envelopes. Figure 18 to 21 illustrate failure mechanisms for selected V-H-M

383 load combinations, considering foundations with embedment ratios $\mathrm{d} / \mathrm{B}=0.1$ and 0.5 ,

384 and both of the strength profiles considered. In each figure, the solid foundation is

385 compared with a series of skirted foundations, beginning with the externally skirted case

386 (zero internal skirts) and showing the transition in failure mechanism as internal skirts

387 are added, up to the point where effective rigidity of the soil plug is achieved and the

388 failure mechanism is essentially identical to that of the solid foundation. Note that the

389 load combinations corresponding to the mechanisms in Figure 18 to 21 are cross-

390 referenced in the failure envelope plots in Figure 13 to 16 respectively.

\subsection{Design recommendation}

392 Figure 22 is a summary plot showing the number of internal skirts necessary for a plane

393 strain skirted foundation to displace with a rigid soil plug, and thus achieve maximum

394 capacity under general V-H-M loading. The critical number of skirts is identified either

395 by convergence of the $\mathrm{H}-\mathrm{M}$ failure envelopes of skirted foundations with $\mathrm{n}$ and $\mathrm{n}+1$

396 internal skirts, or by convergence of the $\mathrm{H}-\mathrm{M}$ failure envelope of the skirted foundation

397 with that of the solid foundation, at every vertical load level. The number of internal

398 skirts required for 'practical' convergence of the failure envelopes, rather than strict

399 coincidence of the failure envelopes, was determined with a certain amount of

400 engineering discretion. For example (as mentioned earlier) considering the results in

401 Figure 13, strictly five internal skirts are required to achieve coincidence of the failure

402 envelope of the skirted foundation with that of the solid foundation, although negligible 
Published in ASCE Journal of Geotechnical and Geoenvironmental Engineering, 139(9):1554-1566. http://dx.doi.org/10.1061/(ASCE)GT.1943-5606.0000882

403 improvement in capacity is achieved with more than two skirts. In this case, the critical

404 number of internal skirts is taken as two.

405 The solid lines in Figure 22 indicate a linear interpolation between the critical (i.e. the

406 minimum) number of internal skirts required to mobilize maximum V-H-M capacity for

407 each of the embedment ratios considered in this study. In practice, interpolated values of

408 the critical number of skirts for intermediate embedment ratios should be rounded up in

409 order to err on the safe side - as indicated by the broken lines in Figure 22.

410 It is clear from Figure 22 that more skirts are required for low skirt embedment ratios

411 and for soils with a high degree of strength heterogeneity. In many cases, more than

412 twice as many internal skirts are required in soil with strength proportional to depth

$413\left(\mathrm{kB} / \mathrm{sum}_{\mathrm{um}}=\infty\right)$ compared with uniform soil $\left(\mathrm{kB} / \mathrm{s}_{\mathrm{um}}=0\right)$ across the range of embedment

414 ratios considered in this study.

415 Figure 22 also reveals a non-linear relationship between the required number of internal

416 skirts and the embedment ratio, with a higher rate of change at low embedment ratios.

417 For $\mathrm{d} / \mathrm{B}>0.2$, the required number of internal skirts begins to stabilize, particularly in

418 the soil with uniform strength. A continued reduction in the required number of internal

419 skirts, and a diminishing effect on bearing capacity of the development of an internal

420 mechanism, is clearly to be expected with increasing embedment ratio. However, there

421 is no evidence here to suggest that increasing the embedment ratio will eventually

422 guarantee soil plug rigidity without the provision of internal skirts. Indeed, it has been

423 noted elsewhere that failure mechanisms for suction caissons, with typical length to

424 diameter ratios in excess of three, can involve an 'inverted scoop' mechanism at the 
Published in ASCE Journal of Geotechnical and Geoenvironmental Engineering, 139(9):1554-1566. http://dx.doi.org/10.1061/(ASCE)GT.1943-5606.0000882

425 base of the soil plug if the center of rotation is located beneath the toe of the caisson

426 (Randolph and House 2002).

427 As discussed above, Figure 22 defines the required number of internal skirts for plug soil rigidity under any combination of V-H-M loading, and efficiencies may be realized

429 if limited vertical loads can be relied upon in-service. In practice, the design of many

430 subsea foundations is dominated by the $\mathrm{H}$ and $\mathrm{M}$ load components, and the design

431 vertical load, V, is less than $25 \%$ of the ultimate vertical capacity, $\mathrm{V}_{\text {ult. }}$ Figure 23 shows

432 the required number of internal skirts needed to achieve maximum H-M capacity under various levels of vertical load, $\mathrm{V} / \mathrm{V}_{\text {ult. }}$ This indicates that fewer skirts are often sufficient

434 if the vertical load is limited. In the case of soil with strength proportional to depth,

435 Figure 23b, a reduction in the required number of internal skirts is achieved over the full 436 range of embedment ratios. For uniform soil, Figure 23 a, efficiencies are only realized 437 for low embedment ratios $(\mathrm{d} / \mathrm{B}<0.2)$. This is because efficiencies of this type can only 438 be achieved for cases where high vertical loading provides the critical case (in terms of 439 the number of skirts required), e.g. in Figure 13. Limiting the applied vertical load will 440 not lead to a reduction in the required number of internal skirts if the critical case is 441 associated with low vertical load, e.g. in Figure 14.

442 The efficiencies available from limiting the vertical load level are relatively modest, 443 even when $\mathrm{kB} / \mathrm{sum}_{\mathrm{um}}=\infty$, with one or at most two internal skirts being saved (although at 444 high embedment ratios this is a reduction by half). This indicates that the required 445 number of internal skirts is governed by the $\mathrm{H}$ and $\mathrm{M}$ components of loading, rather 446 than the V component. As such, explicit consideration of the horizontal and moment 447 loading applied to a skirted foundation should form an essential part of the design. 
Published in ASCE Journal of Geotechnical and Geoenvironmental Engineering, 139(9):1554-1566. http://dx.doi.org/10.1061/(ASCE)GT.1943-5606.0000882

\subsection{Practical considerations}

449 The curves presented in Figure 23 provide a practical guideline for determining the

450 minimum number of internal skirts. However, the data should be treated with caution

451 and considered with regard to the following points:

452

- These results have been derived for idealized material characteristics, foundation

453 geometries and interface conditions. In practice, a variety of other factors (e.g.

454 strength anisotropy) may affect the maximum load-carrying capacity, and there may

455 also be installation problems (e.g. tilting, or failure to achieve full skirt penetration)

456 that affect the effective embedment depth achieved.

457

- The present investigation is restricted to an idealized two-dimensional (plane strain)

458 cross-section through a skirted foundation. In the case of a square, circular or

459 rectangular skirted foundation, significant three-dimensional effects may be present

460 in the failure mechanisms under various load combinations, and the results

461 presented in Figure 22 and 23 would be expected to provide a conservative

462 prediction of the required number of internal skirts.

- In reality, a foundation with very short skirts placed on soil with low mudline

464 strength will tend to settle until sufficient bearing capacity is achieved, resulting in a

465 higher effective embedment and thus a reduction in the required number of internal

466 skirts. For example, a foundation with $\mathrm{d} / \mathrm{B}=0.05$ placed on a soil with (near) zero

467 mudline strength may not require the full complement of five or six internal skirts as

468 indicated by the results presented in Figure 22 and 23. Conversely, unanticipated

469 soil plug heave during installation, or scour around the foundation, may reduce the

470 effective embedment depth, leading to insufficient internal skirts being provided to

471 ensure rigidity of the soil plug, and an associated reduction in foundation capacity. 
Published in ASCE Journal of Geotechnical and Geoenvironmental Engineering, 139(9):1554-1566. http://dx.doi.org/10.1061/(ASCE)GT.1943-5606.0000882

\section{Concluding remarks}

473 This paper has presented results from an extensive numerical study, carried out using

474 finite element limit analysis, of the undrained capacity of shallow skirted foundations

475 under general V-H-M loading. In particular, the focus has been on the critical number of

476 internal foundation skirts necessary to ensure that the soil plug confined by a skirted

477 foundation displaces rigidly, such that maximum foundation load-carrying capacity

478 (equivalent to that of a corresponding solid foundation) can be mobilized.

479 The critical number of internal skirts has been identified for skirt embedments ranging

480 from $5 \%$ to $50 \%$ of the foundation breadth, considering soils with both uniform strength

481 and strength proportional to depth (representing the extremes of the generic linearly

482 varying strength profile characterized by the dimensionless parameter $\mathrm{kB} / \mathrm{s}_{\mathrm{um}}$ ). The

483 results indicate that the skirt embedment, the degree of strength heterogeneity and the

484 level of applied vertical load all have significant influences on the number of internal

485 skirts required. The critical number of internal skirts has been quantified by constructing

486 numerous V-H-M failure envelopes, and by studying the corresponding failure

487 mechanisms. The overall findings have been summarized in graphical form (Figure 22

488 and 23) as a function of the key variables.

489 The results presented provide practical guidance on the minimum number of foundation

490 skirts that should be provided to prevent an internal mechanism developing within the

491 soil plug, thereby allowing the optimum load carrying capacity of a skirted foundation

492 to be realized. Further research is required to extend these findings to general loading of

493 skirted foundations with three-dimensional geometries. 
Published in ASCE Journal of Geotechnical and Geoenvironmental Engineering, 139(9):1554-1566. http://dx.doi.org/10.1061/(ASCE)GT.1943-5606.0000882

494

495

496 The work described in this Paper forms part of the activities of the Special Research

497 Centre for Offshore Foundation Systems (COFS), currently supported as a node of the

498 Australian Research Council Centre of Excellence for Geotechnical Science and

499 Engineering. The work presented in this paper was supported through ARC grant

500 DP0988904. This support is gratefully acknowledged.

501 The work was carried out during an academic visit of the first and second authors to the

502 Department of Engineering Science, University of Oxford, UK. The support of the

503 Department of Engineering Science and the University of Oxford is gratefully

504 acknowledged. MatLab scripting advice from Prof. David White is also gratefully

505 acknowledged.

506 
Published in ASCE Journal of Geotechnical and Geoenvironmental Engineering, 139(9):1554-1566. http://dx.doi.org/10.1061/(ASCE)GT.1943-5606.0000882

\section{REFERENCES}

508

API (2000). Recommended practice for planning, designing and constructing fixed offshore platforms working stress design. API RP-2A, American Petroleum Institute, Washington, USA.

Andersen, K.H. and Jostad, H.P. (1999). "Foundation design of skirted foundations and anchors in clay.” Proc. Annual Offshore Technology Conf., Houston, Paper OTC 10824.

Bransby, M.F. and Yun, G. (2009). “The undrained capacity of skirted strip foundations under combined loading.” Géotechnique 59(2), 115-125.

Bye, A., Erbrich, C., Rognlien, B. and Tjelta, T.I. (1995). “Geotechnical design of bucket foundations.” Proc. Annual Offshore Technology Conf., Houston, Paper OTC 7793.

Dassault Systèmes (2009). Abaqus analysis users’ manual. Simulia Corp., Providence, RI, USA.

Davis, E.H. and Booker, J.R. (1973). "The effect of increasing strength with depth on the bearing capacity of clays.” Géotechnique 23(4), 551-563.

Dyvik, R., Andersen, K.H., Hansen, S.B. and Christophersen, H.P. (1993). "Field tests of anchors in clay.” I: Description. J. Geotech. Engng., ASCE 199(10), 1515-1531.

Erbrich, C. and Hefer, P. (2002). "Installation of the Laminaria suction piles - a case history.” Proc. Annual Offshore Technology Conf., Houston, Paper OTC 14240.

Gourvenec, S. and Barnett, S. (2011). “Undrained failure envelope for skirted foundations under general loading.” Géotechnique 61(3), 263-270.

Gourvenec, S., Acosta-Martinez, H.E. and Randolph, M.F. (2009). "Experimental study of uplift resistance of shallow skirted foundations in clay under concentric transient and sustained loading.” Géotechnique 59(6), 525-537. 
Published in ASCE Journal of Geotechnical and Geoenvironmental Engineering, 139(9):1554-1566. http://dx.doi.org/10.1061/(ASCE)GT.1943-5606.0000882

528 ISO (2003). Petroleum and natural gas industries - Specific requirements for offshore structures - Part

529 4: Geotechnical and foundation design considerations. ISO 19901-4:2003, International Organization

530 for Standardization.

531 Kusakabe, O. Suzuke, H. and Nakase, A. (1986). “An upper bound calculation on bearing capacity of a 532 circular footing on a non-homogeneous clay.” Soils and Foundations 26(3), 143-148.

533 Makrodimopoulos, A. and Martin, C.M. (2006). "Lower bound limit analysis of cohesive-frictional 534 materials using second-order cone programming." International Journal for Numerical Methods in $535 \quad$ Engineering 66(4), 604-634.

536 Makrodimopoulos, A. and Martin, C.M. (2007). "Upper bound limit analysis using simplex strain elements and second-order cone programming." International Journal for Numerical and Analytical Methods in Geomechanics31(6), 835-865.

539

Makrodimopoulos, A. and Martin, C.M. (2008). "Upper bound limit analysis using discontinuous quadratic displacement fields.” Communications in Numerical Methods in Engineering 24(11), 911-

Mana, D.S.K., Gourvenec, S. and Randolph, M.F. (2010). “A numerical study of the vertical bearing capacity of skirted foundations.” Proc. $2^{\text {nd }}$ Int. Symp. Front. Off. Geotech. (ISFOG), Perth, 433-438. foundations in uplift and compression.” International Journal of Physical Modelling in Geotechnics 12(2), 47-62.

547

Martin, C.M. and Randolph, M.F. (2001). "Applications of the lower and upper bound theorems of plasticity to collapse of circular foundations.” Proc. 10 $0^{\text {th }}$ Int. Conf. Int. Assoc. Comp. Meth. Adv. Geomech. (IACMAG), Tucson, 1417-1428. 
Published in ASCE Journal of Geotechnical and Geoenvironmental Engineering, 139(9):1554-1566. http://dx.doi.org/10.1061/(ASCE)GT.1943-5606.0000882

552 MOSEK ApS (2010). The MOSEK optimization tools manual, Version 5. Available online at $553 \quad$ www.mosek.com.

554 Prandtl, L. (1921). “Eindringungsfestigkeit und festigkeit von schneiden.” Angew. Math. U. Mech 1(15).

555 Randolph M.F. and House A.R. (2002). “Analysis of suction caisson capacity in clay.” Proc. Annual

556 Offshore Technology Conf., Houston, Paper OTC 14236.

557 Shewchuk, J.R. (2002). “Delaunay refinement algorithms for triangular mesh generation.” Computational $558 \quad$ Geometry 22(1-3), 21-74.

559 Watson, P.G., Randolph, M.F. and Bransby, M.F. (2000). “Combined lateral and vertical loading of 560 caisson foundations.” Proc. Annual Offshore Technology Conf., Houston, Paper OTC 12195.

561 Yun, G. and Bransby, M.F. (2007). "The undrained vertical bearing capacity of skirted foundations.” $562 \quad$ Soils and Foundations 47(3), 493-505. 
Published in ASCE Journal of Geotechnical and Geoenvironmental Engineering, 139(9):1554-1566. http://dx.doi.org/10.1061/(ASCE)GT.1943-5606.0000882

\section{FIGURE CAPTIONS}

Figure 1 Characteristics of an idealized skirted foundation

Figure 2. Examples of failure mechanisms of solid and skirted shallow foundations under (a) pure vertical load and (b) pure horizontal load

Figure 3 Definition of terminology to describe solid and skirted foundations

Figure 4 Definition of soil strength profiles

Figure 5 Sign convention and nomenclature

Figure 6 Load probes and definition of failure envelopes

Figure 7 Comparison of V-H-M failure envelopes predicted with OxLim and Abaqus: rough-based surface strip foundation on a deposit with uniform shear strength

Figure 8 Vertical bearing capacity of solid and skirted foundations for (a) $\mathrm{kB} / \mathrm{s}_{\mathrm{um}}=0$ and (b) $\mathrm{kB} / \mathrm{s}_{\mathrm{um}}=\infty$

Figure 9 Soil velocity vectors accompanying vertical bearing failure of solid and externally skirted foundations for $\mathrm{kB} / \mathrm{s}_{\mathrm{um}}=0$. Examples showing (a) $\mathrm{d} / \mathrm{B}=0.1$ and (b) $\mathrm{d} / \mathrm{B}=0.5$

Figure 10 Soil velocity vectors accompanying vertical bearing failure of solid and skirted foundations for $\mathrm{kB} / \mathrm{s}_{\mathrm{um}}=\infty$ and low embedment ratio, $\mathrm{d} / \mathrm{B}=0.1$

Figure 11 Soil velocity vectors accompanying vertical bearing failure of solid and externally skirted foundations for $\mathrm{kB} / \mathrm{sum}_{\mathrm{um}}=\infty$ and high embedment ratio, $\mathrm{d} / \mathrm{B}=0.5$

Figure 12 Hill- and Prandtl-type failure mechanisms for a shallow foundation under pure vertical load

Figure 13 Failure envelopes for $\mathrm{kB} / \mathrm{sum}_{\mathrm{um}}=0$ and $\mathrm{d} / \mathrm{B}=0.1$

Figure 14 Failure envelopes for $\mathrm{kB} / \mathrm{sum}_{\mathrm{um}}=0$ and $\mathrm{d} / \mathrm{B}=0.5$

Figure 15 Failure envelopes for $\mathrm{kB} / \mathrm{s}_{\mathrm{um}}=\infty$ and $\mathrm{d} / \mathrm{B}=0.1$ 
Published in ASCE Journal of Geotechnical and Geoenvironmental Engineering, 139(9):1554-1566. http://dx.doi.org/10.1061/(ASCE)GT.1943-5606.0000882

Figure 16 Failure envelopes for $\mathrm{kB} / \mathrm{s}_{\mathrm{um}}=\infty$ and $\mathrm{d} / \mathrm{B}=0.5$

Figure 17 Failure envelope for $\mathrm{kB} / \mathrm{s}_{\mathrm{um}}=\infty$ and $\mathrm{d} / \mathrm{B}=0.05$

Figure 18 Soil velocity vectors at failure for $\mathrm{kB} / \mathrm{s}_{\mathrm{um}}=0$ and $\mathrm{d} / \mathrm{B}=0.1$; loading $\mathrm{V}=0, \mathrm{M} / \mathrm{B}: \mathrm{H}=0.577$

Figure 19 Soil velocity vectors at failure for $\mathrm{kB} / \mathrm{s}_{\mathrm{um}}=0$ and $\mathrm{d} / \mathrm{B}=0.5$; loading $\mathrm{V}=0, \mathrm{M} / \mathrm{B}: \mathrm{H}=0.577$

Figure 20 Soil velocity vectors at failure for $\mathrm{kB} / \mathrm{sum}_{\mathrm{um}}=\infty$ and $\mathrm{d} / \mathrm{B}=0.1$; loading $\mathrm{V}=0.75 \mathrm{Vult}, \mathrm{M} / \mathrm{B}: \mathrm{H}=-1$

Figure 21 Soil velocity vectors at failure for $\mathrm{kB} / \mathrm{s}_{\mathrm{um}}=\infty$ and $\mathrm{d} / \mathrm{B}=0.5$; loading $\mathrm{V}=0.75 \mathrm{Vult}, \mathrm{M} / \mathrm{B}: \mathrm{H}=1$

Figure 22 Number of internal foundation skirts required to mobilize maximum V-H-M capacity

Figure 23 Number of internal foundation skirts required to mobilize maximum H-M capacity under various levels of vertical load for (a) $\mathrm{kB} / \mathrm{sum}_{\mathrm{um}}=0$ and (b) $\mathrm{kB} / \mathrm{sum}=\infty$ 


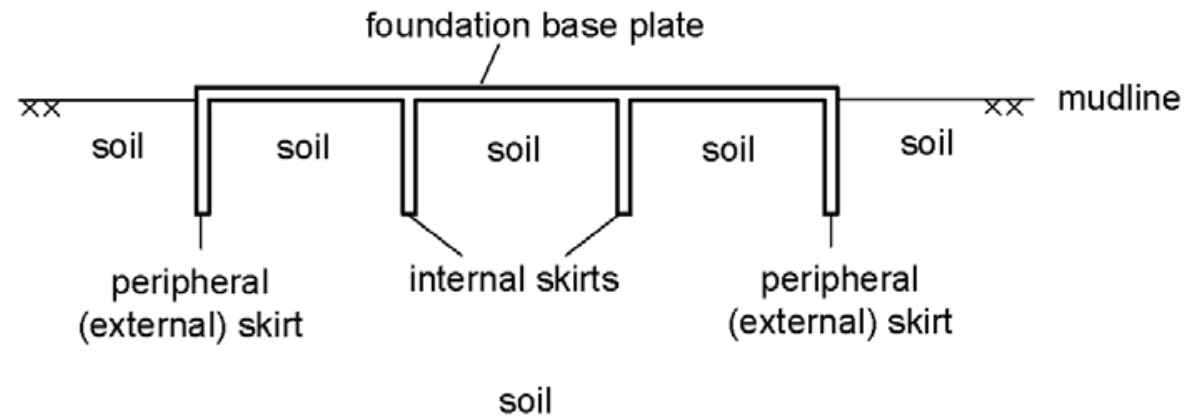

Figure 1
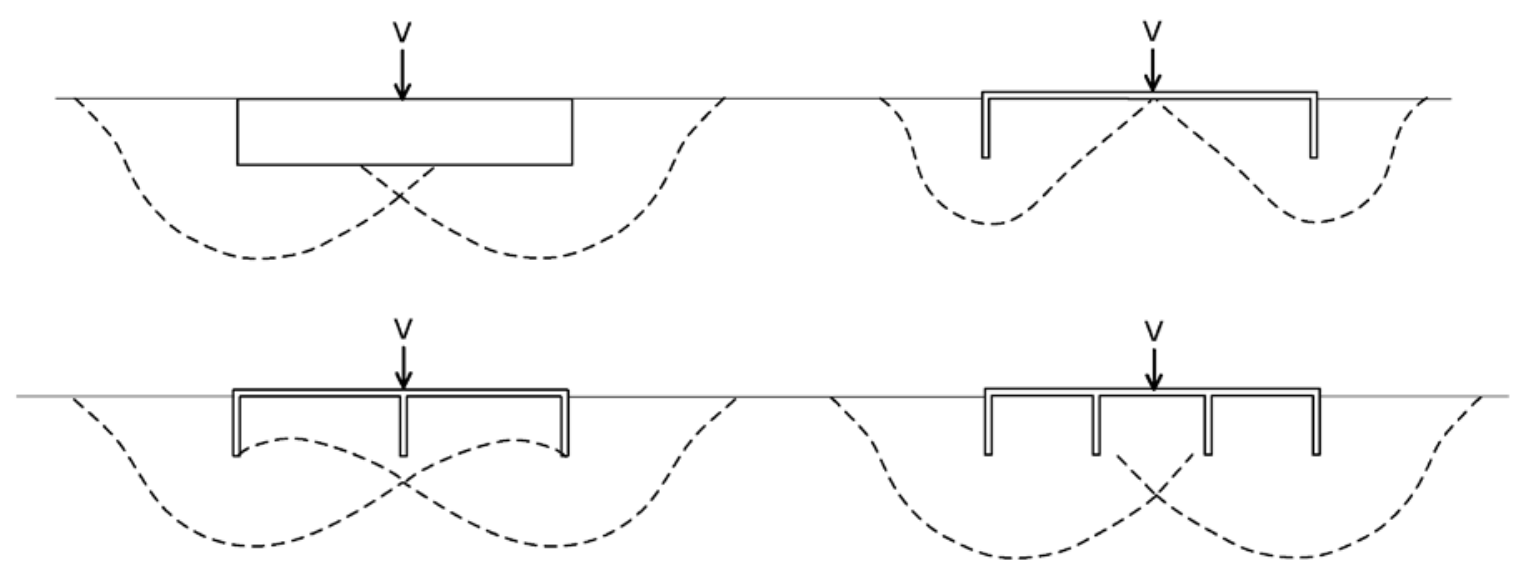

(a)

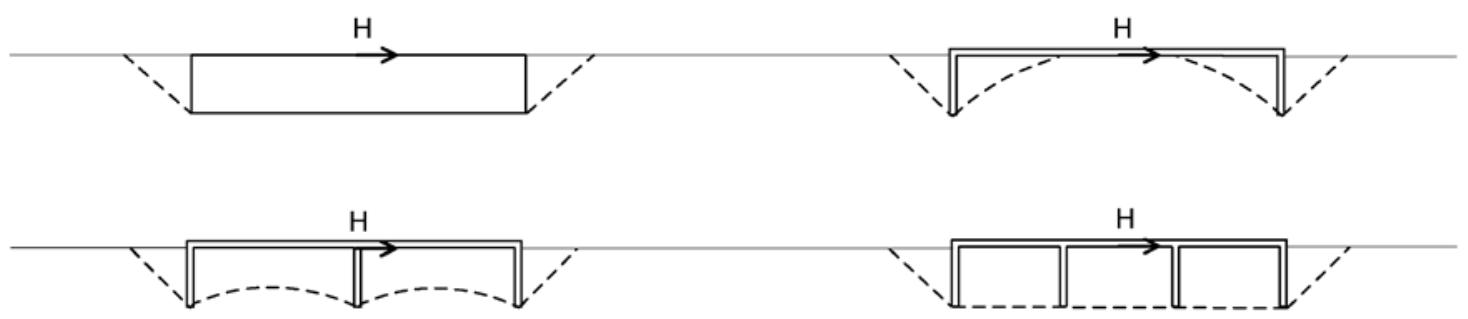

(b)

Figure 2 


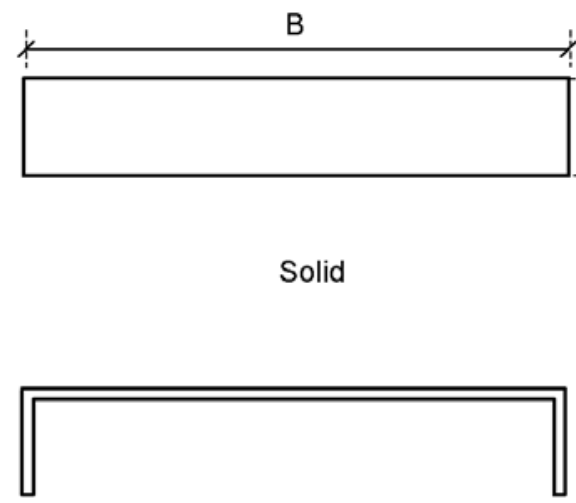

Skirted: zero internal skirts

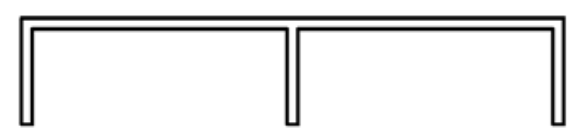

Skirted: 1 internal skirt

Figure 3

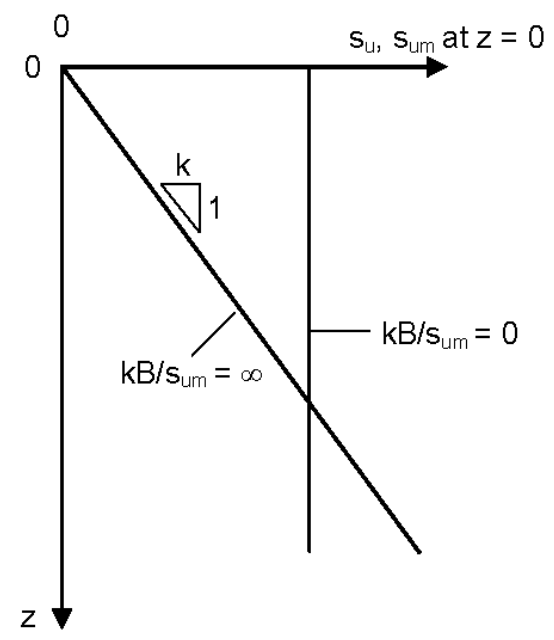

Figure 4 


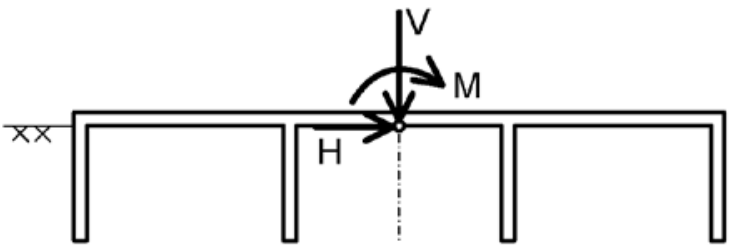

Positive loads and moment shown

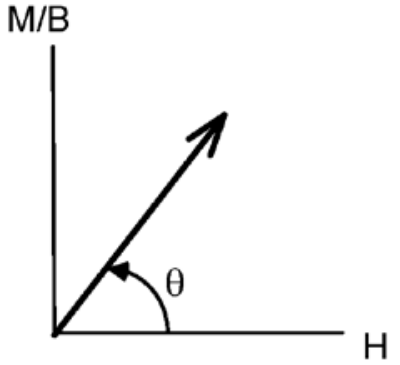

Figure 5

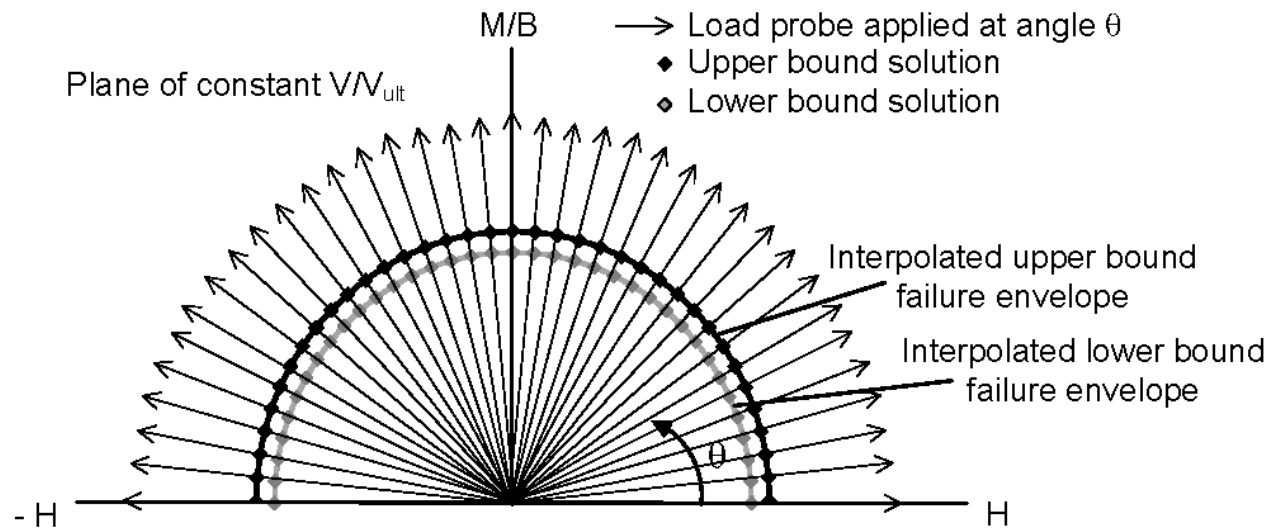

Note: difference between upper and lower bound solutions is exaggerated for clarity (default $<1 \%$ )

Figure 6 


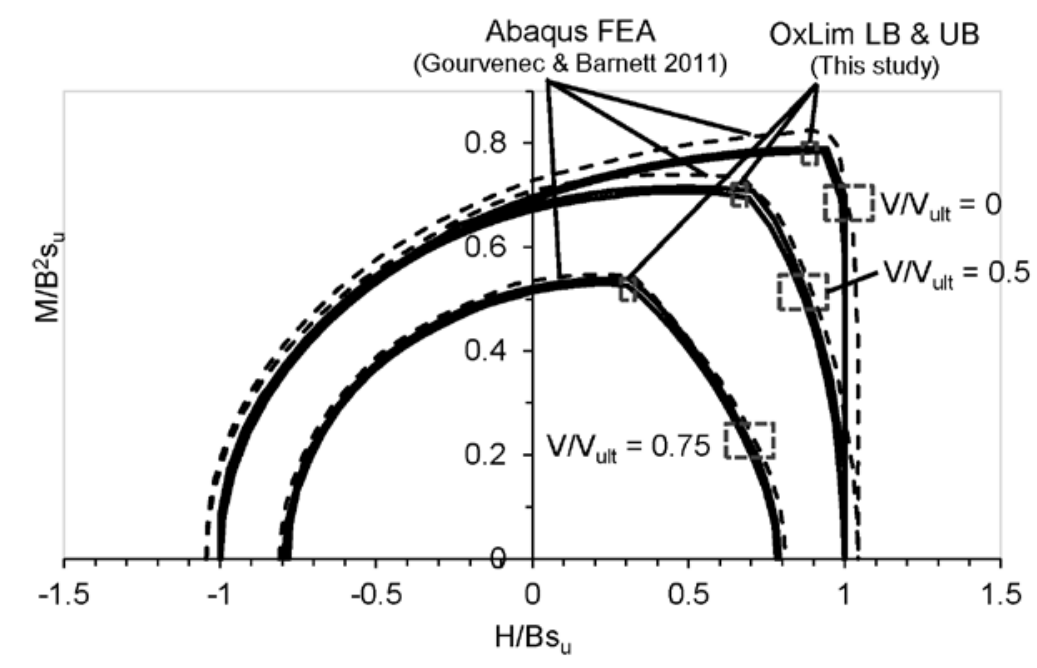

Figure 7
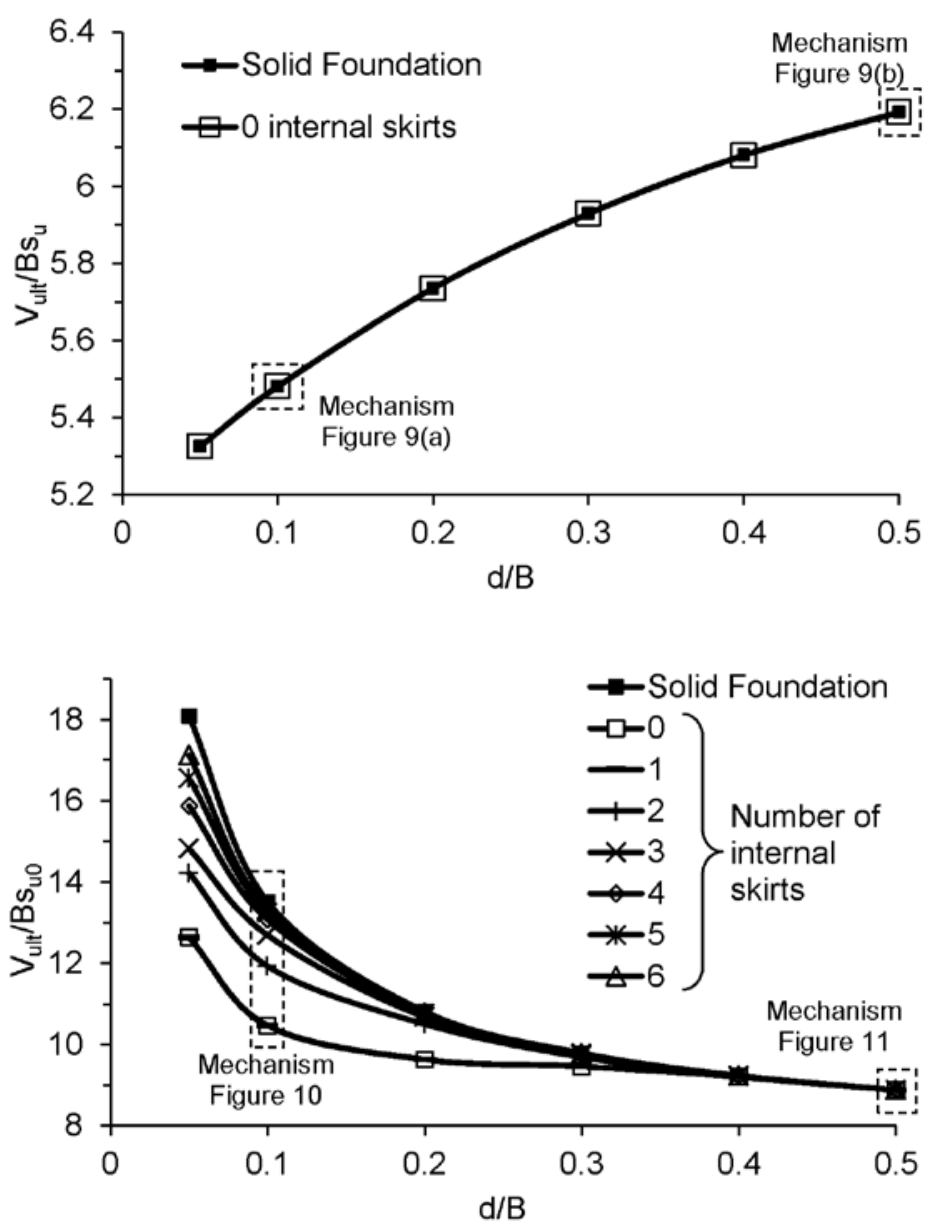

Figure 8 


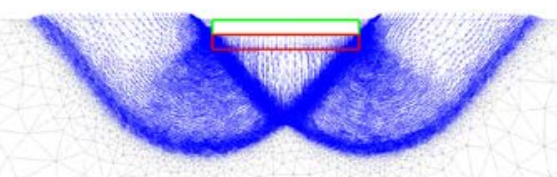

Solid

(a)
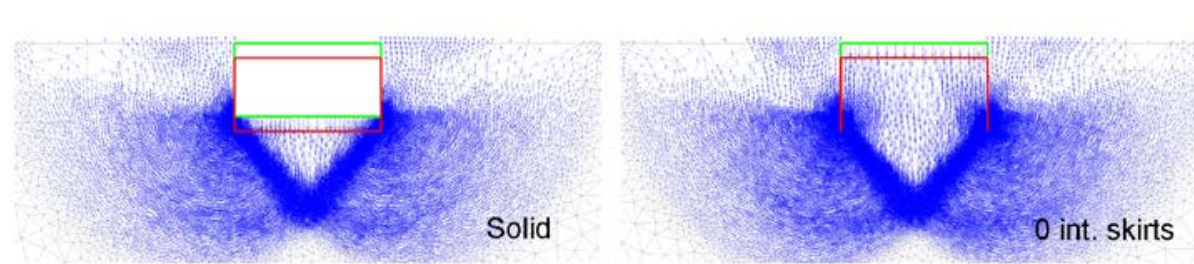

(b)

Figure 9

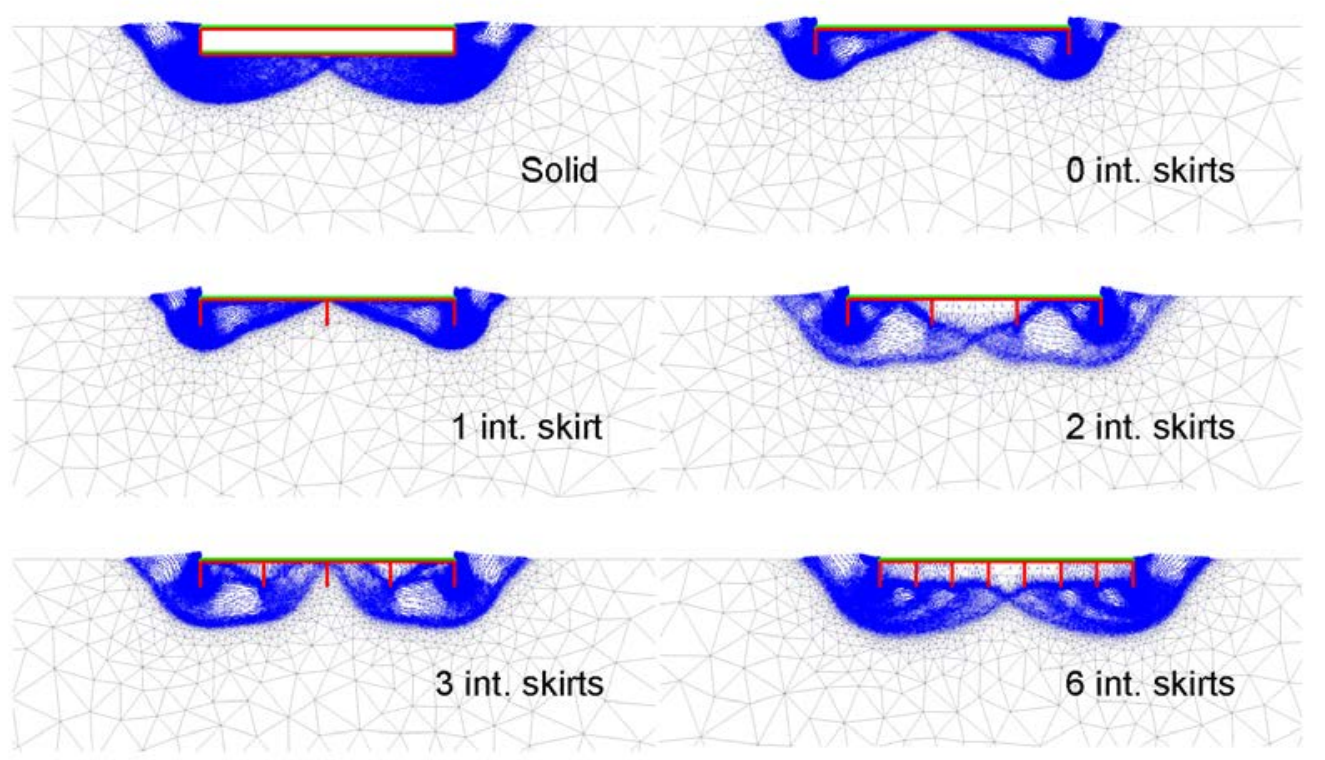

Figure 10
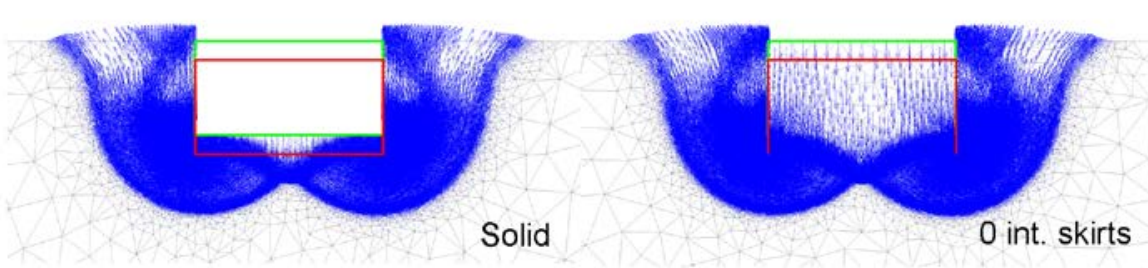

Figure 11 


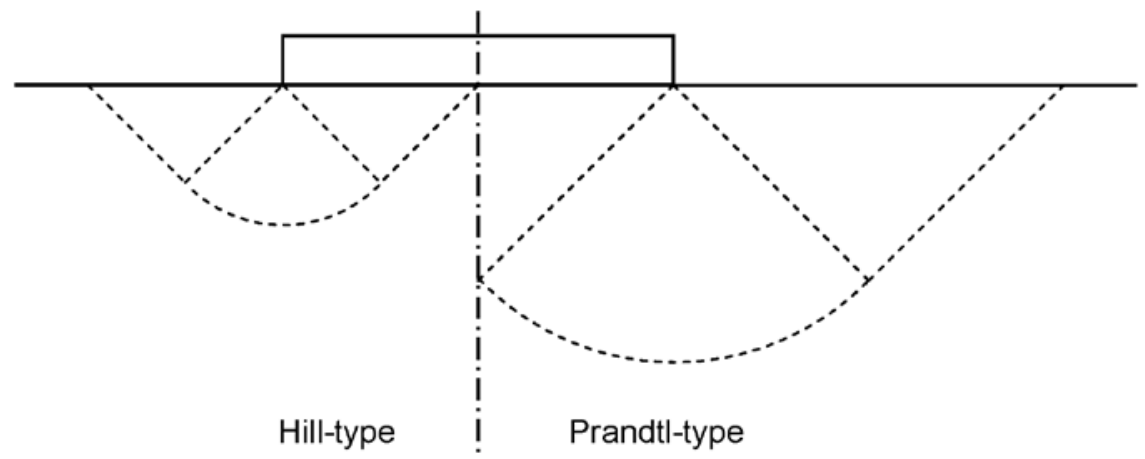

Figure 12 

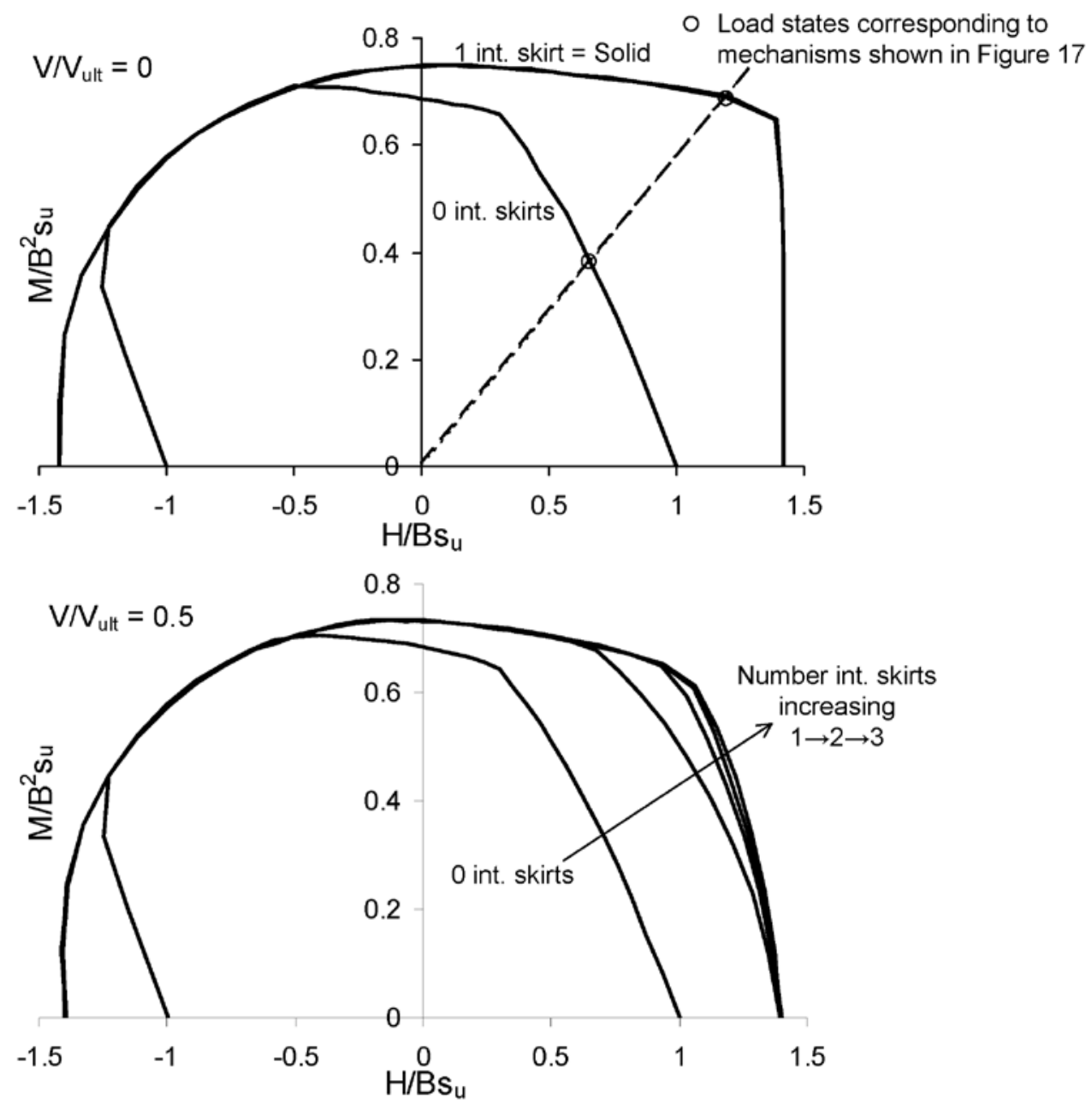

0.8

$\mathrm{V} / \mathrm{V}_{\text {ult }}=0.75$

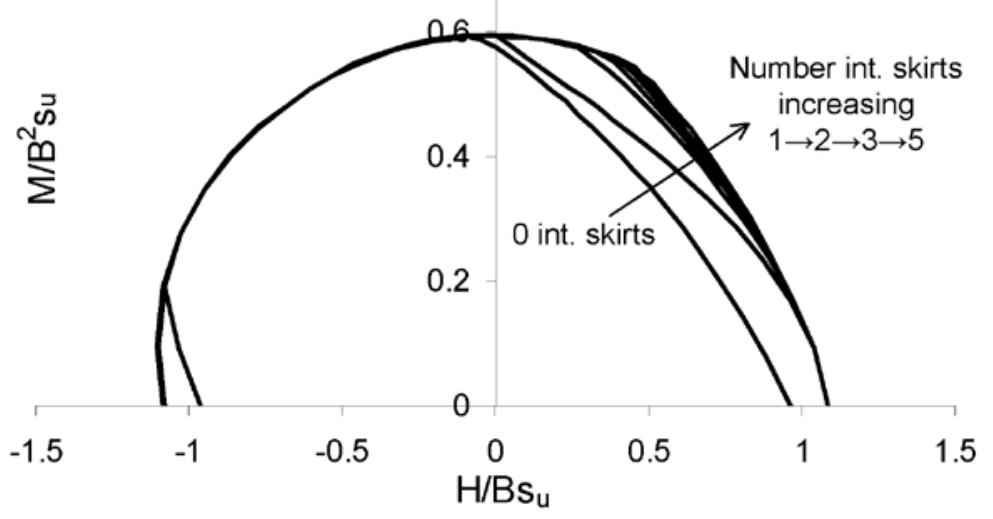

Figure 13 

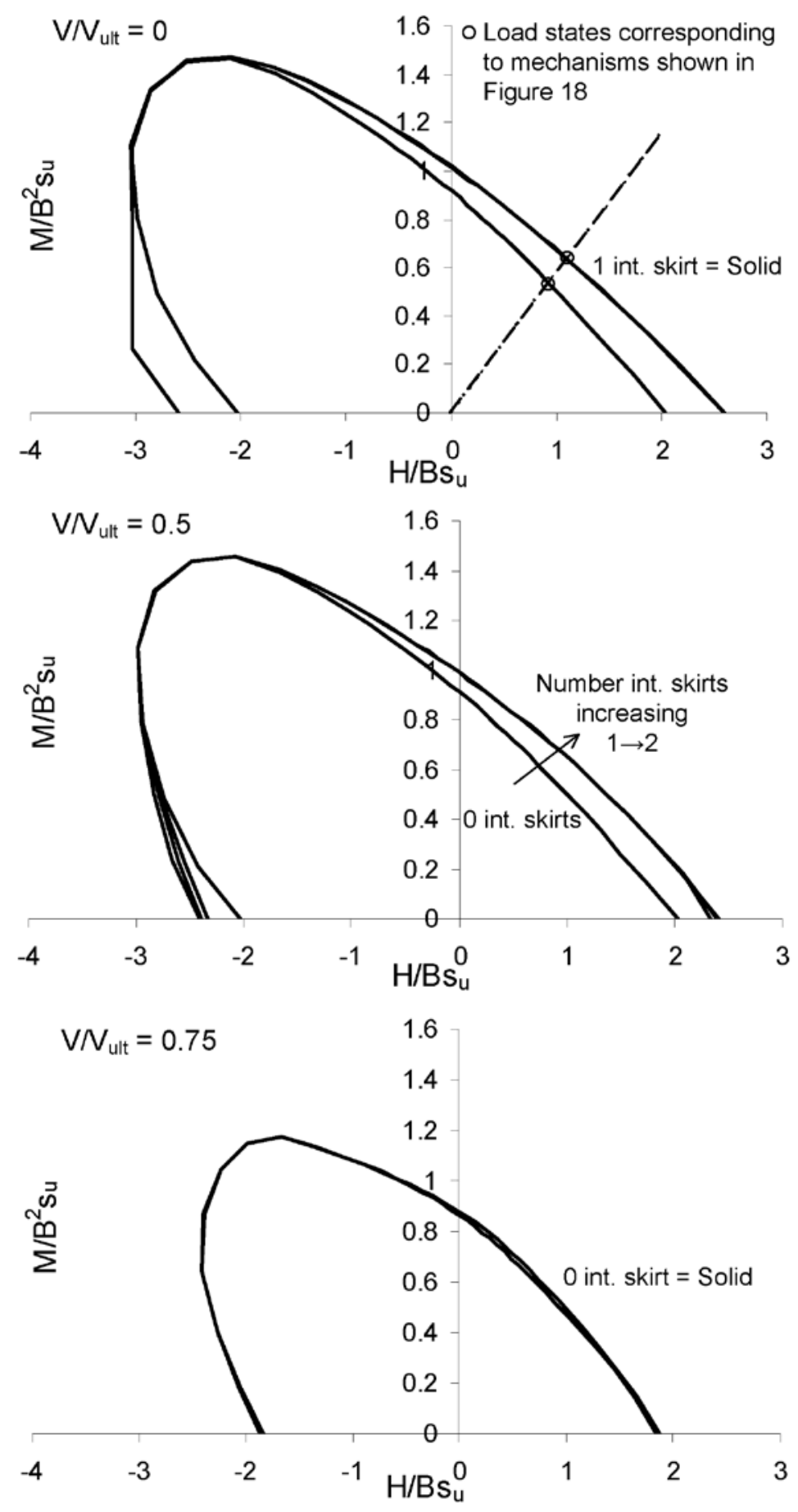

Figure 14 


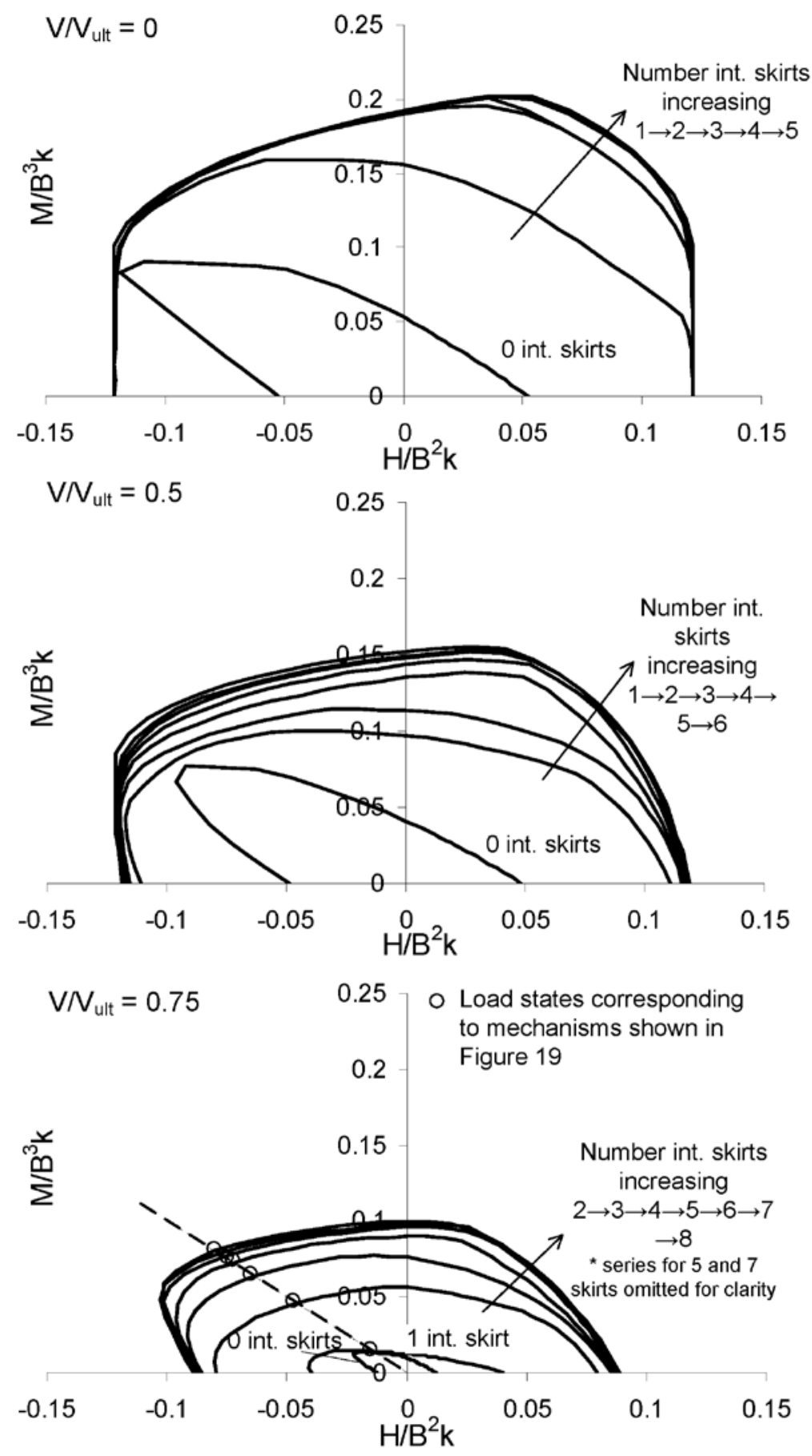

Figure 15 

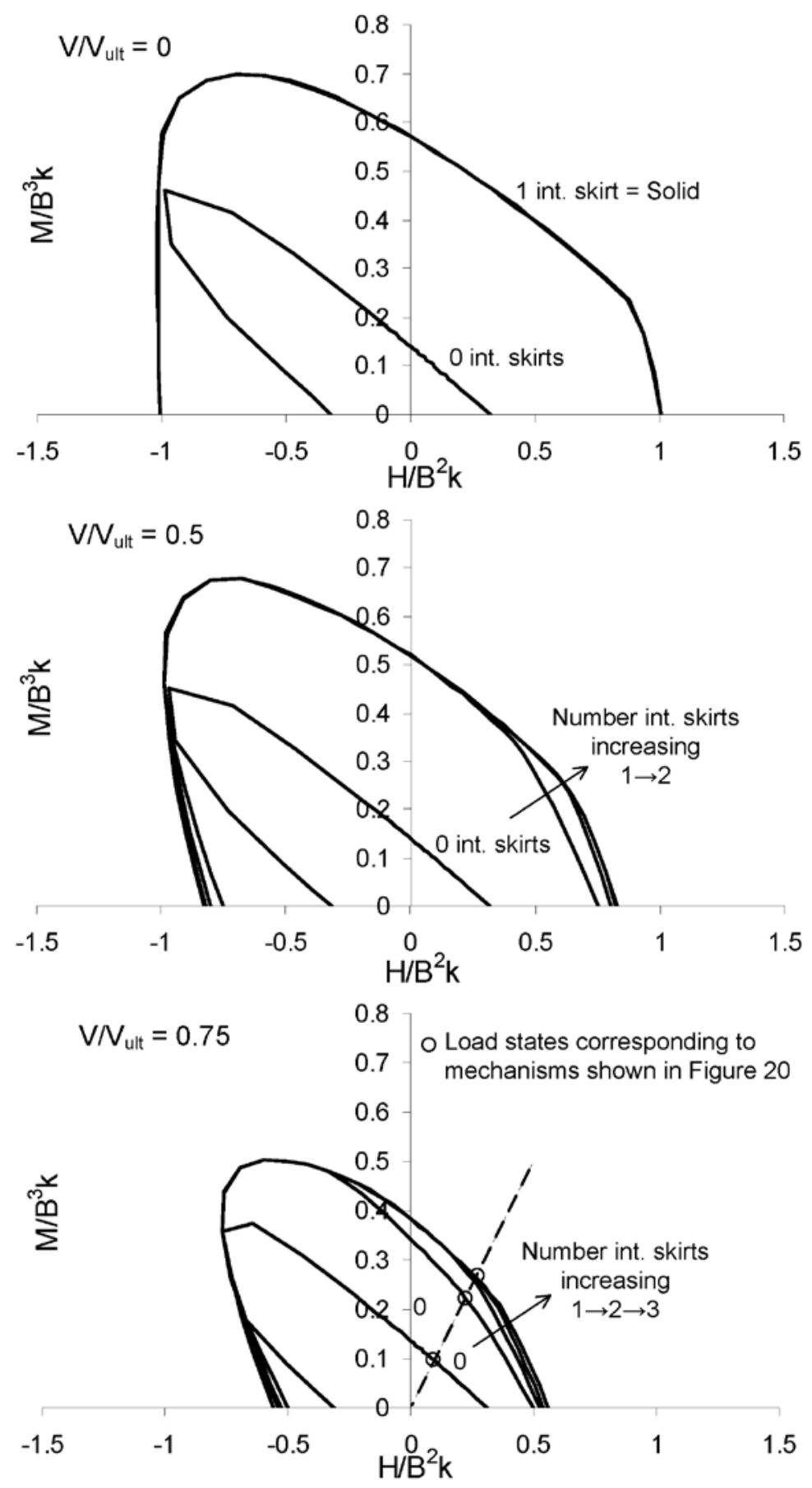

Figure 16 

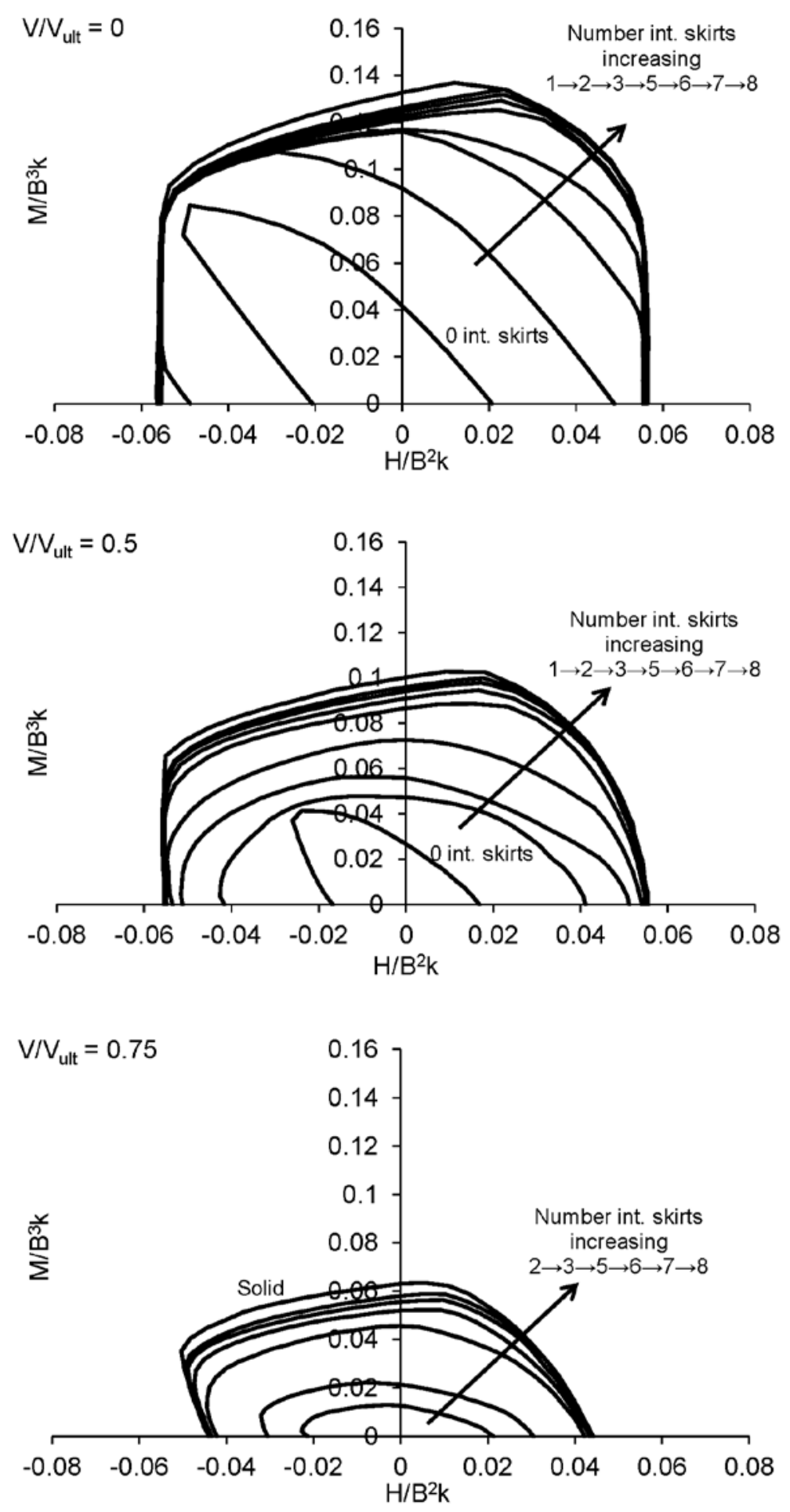

Figure 17 


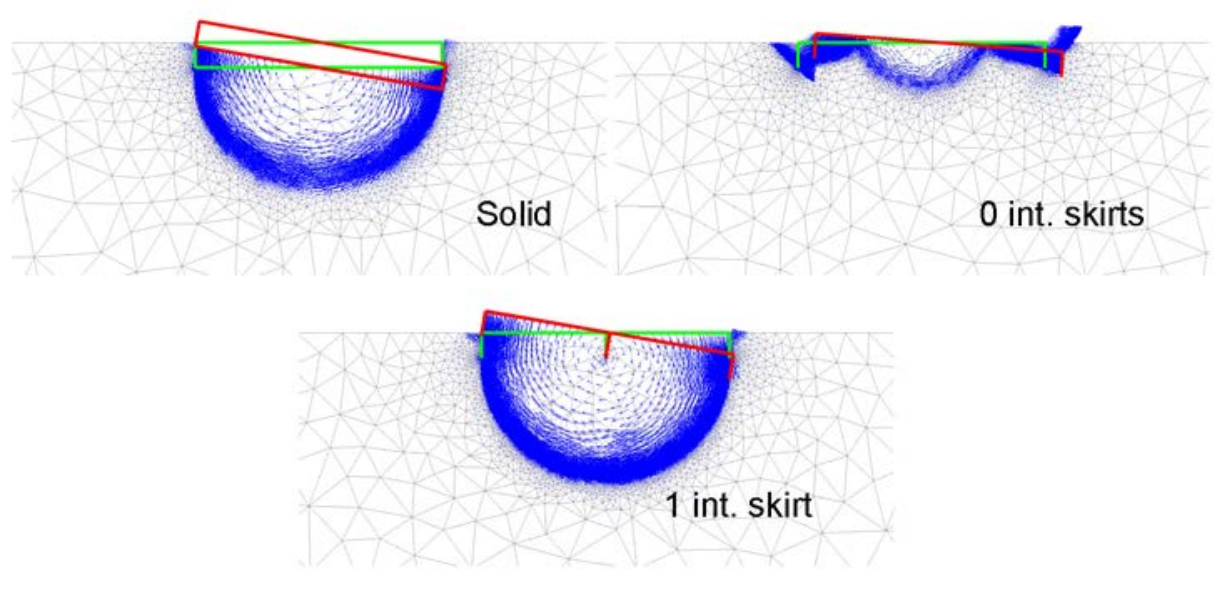

Figure 18

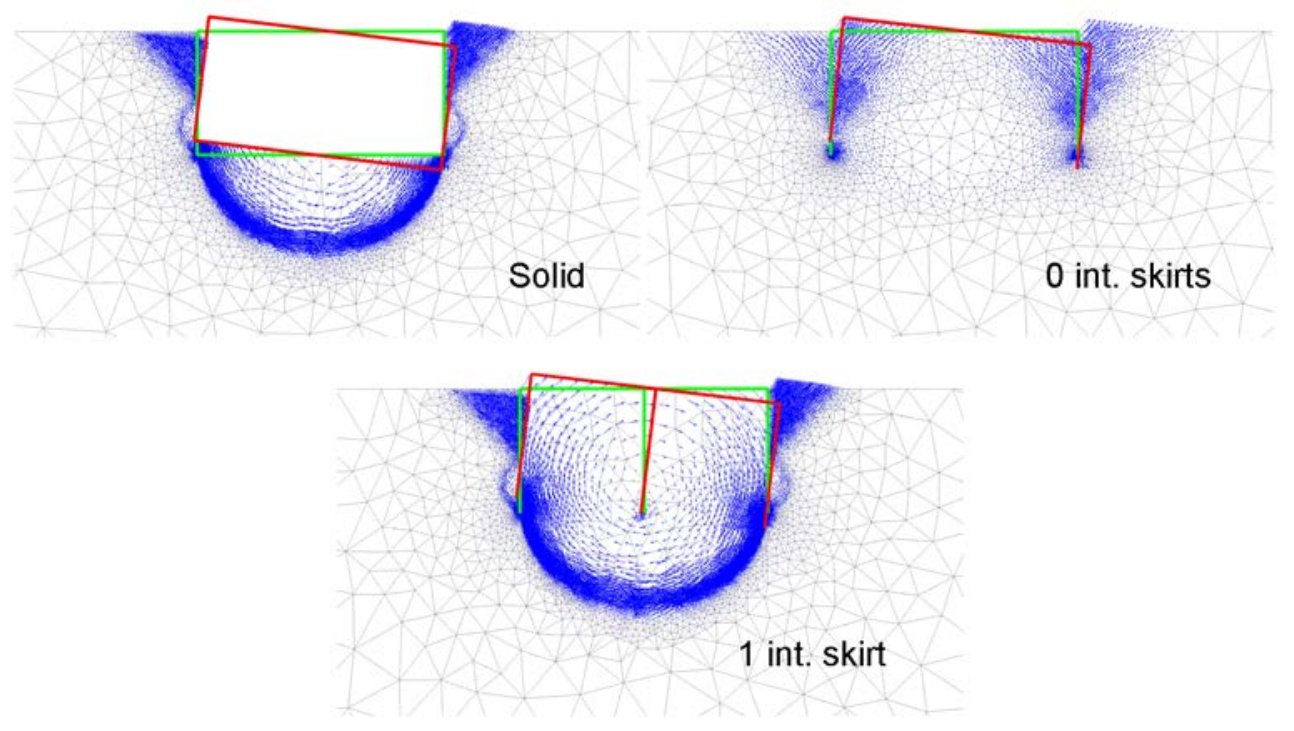

Figure 19 


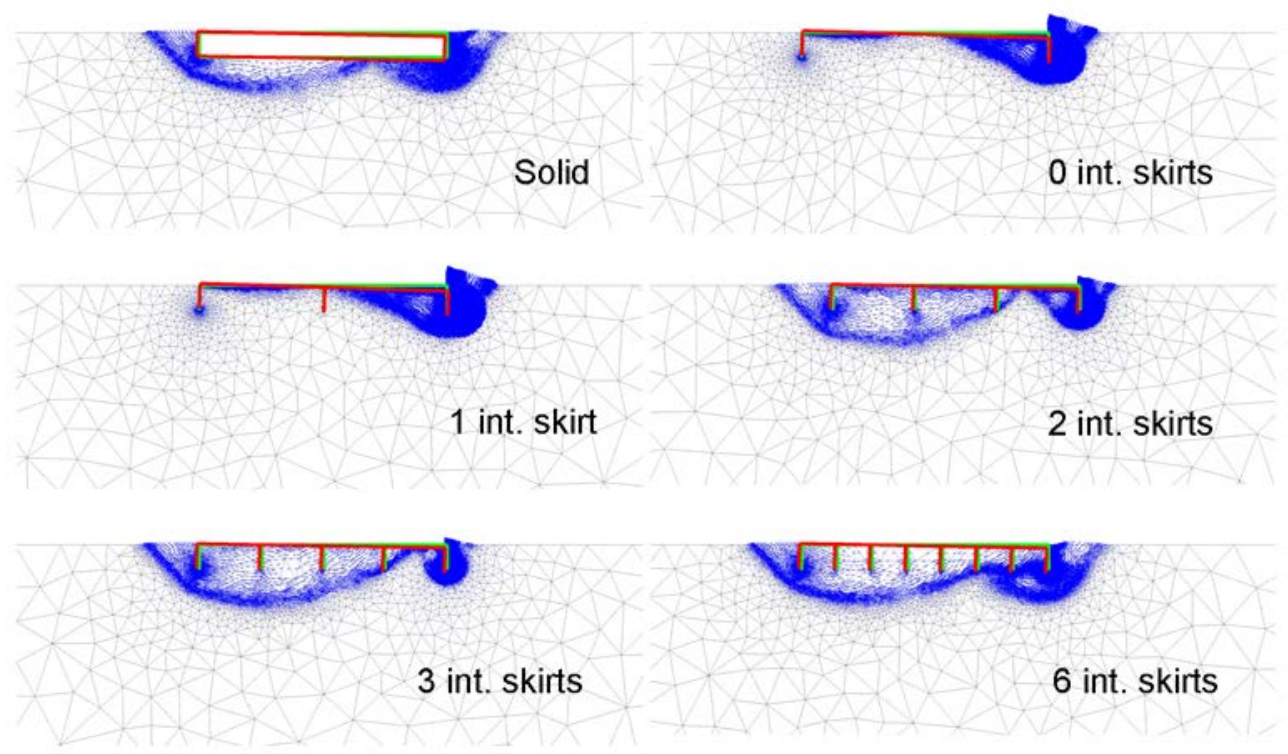

Figure 20

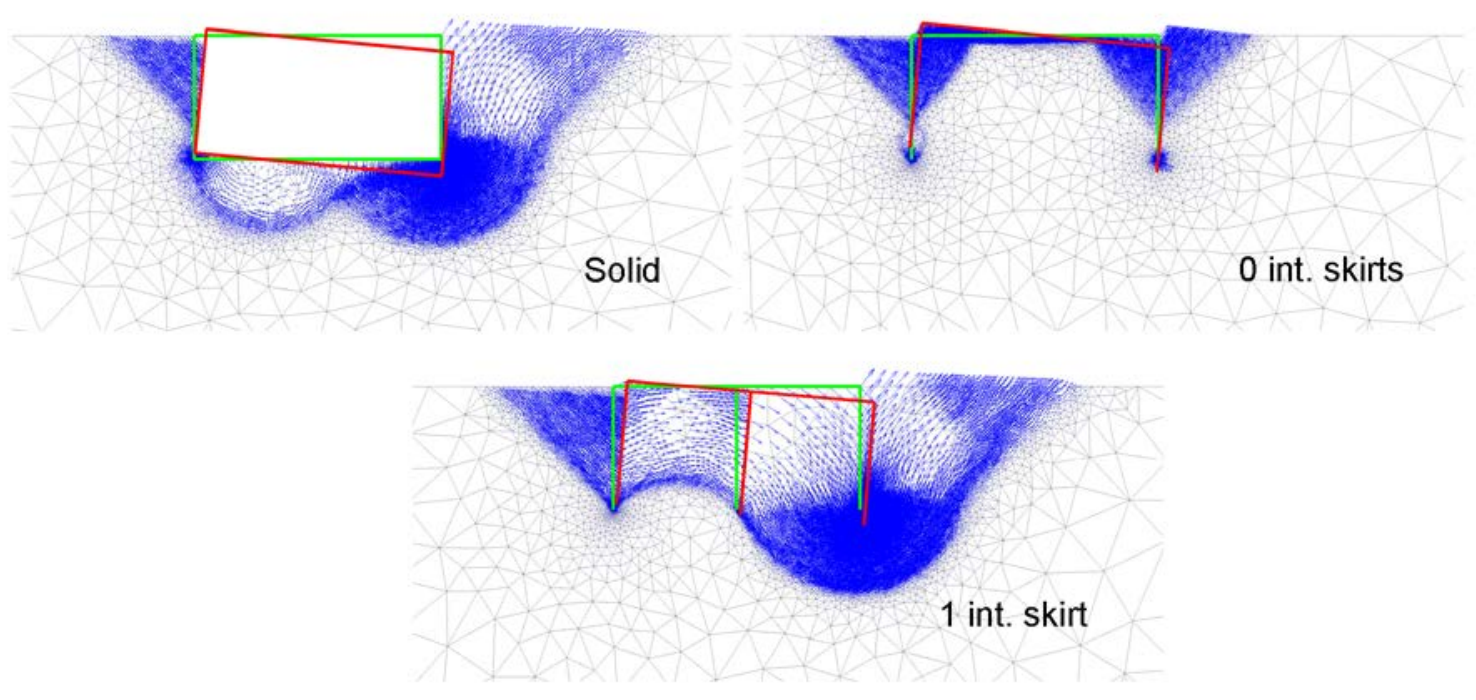

Figure 21 


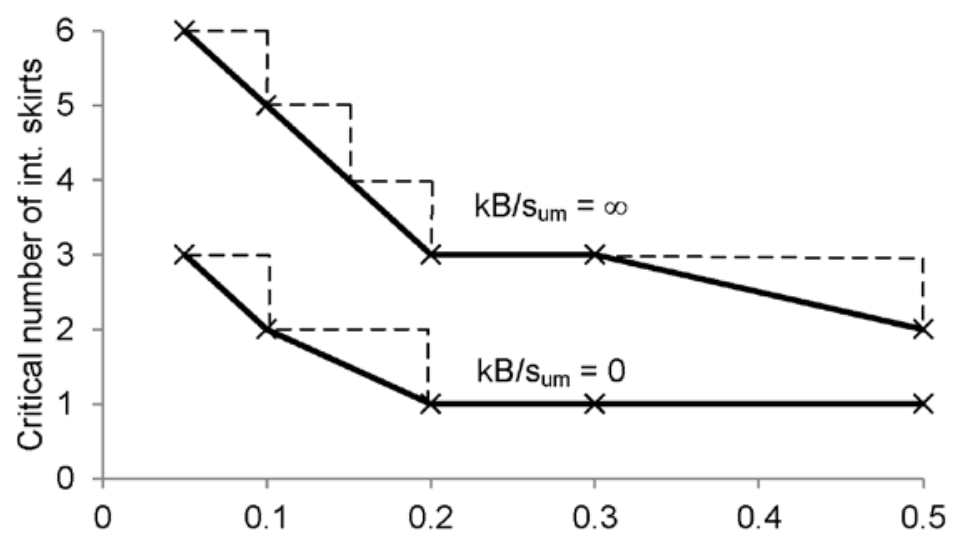

Figure 22

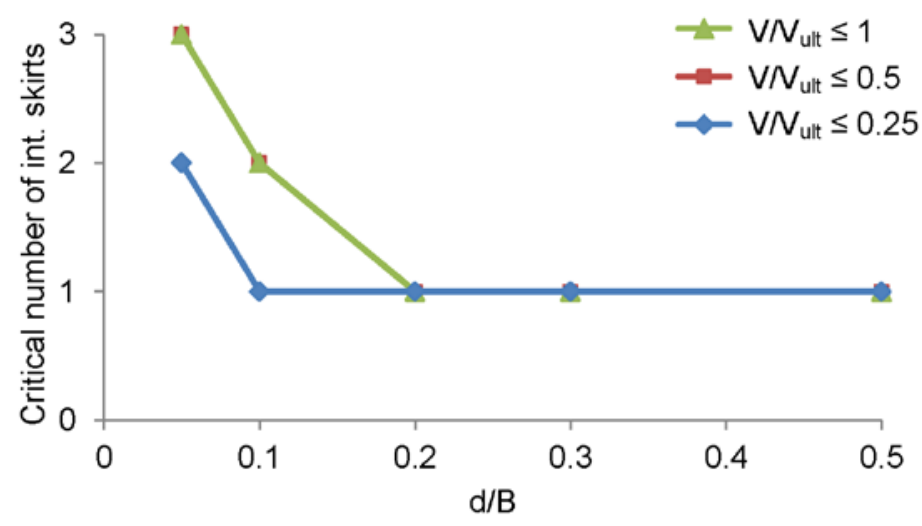

(a)

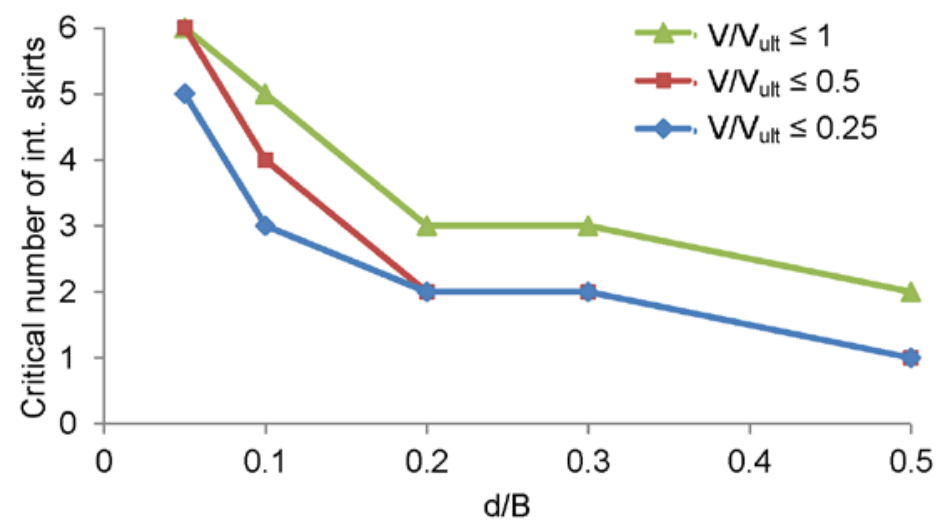

(b)

Figure 23 